\title{
Deep brain stimulation for psychiatric disorders: where we are now
}

\author{
Daniel R. Cleary, MD, PhD, ${ }^{1}$ Alp Ozpinar, BS, ${ }^{2}$ Ahmed M. Raslan, MD, ${ }^{2}$ and Andrew L. Ko, MD ${ }^{3}$ \\ 'Department of Neurology, Yale Medical School, New Haven, Connecticut; '2Department of Neurological Surgery, Oregon \\ Health \& Science University, Portland, Oregon; and 'Department of Neurological Surgery, University of Washington, Seattle, \\ Washington
}

\begin{abstract}
Fossil records showing trephination in the Stone Age provide evidence that humans have sought to influence the mind through physical means since before the historical record. Attempts to treat psychiatric disease via neurosurgical means in the 20th century provided some intriguing initial results. However, the indiscriminate application of these treatments, lack of rigorous evaluation of the results, and the side effects of ablative, irreversible procedures resulted in a backlash against brain surgery for psychiatric disorders that continues to this day. With the advent of psychotropic medications, interest in invasive procedures for organic brain disease waned.

Diagnosis and classification of psychiatric diseases has improved, due to a better understanding of psychiatric pathophysiology and the development of disease and treatment biomarkers. Meanwhile, a significant percentage of patients remain refractory to multiple modes of treatment, and psychiatric disease remains the number one cause of disability in the world. These data, along with the safe and efficacious application of deep brain stimulation (DBS) for movement disorders, in principle a reversible process, is rekindling interest in the surgical treatment of psychiatric disorders with stimulation of deep brain sites involved in emotional and behavioral circuitry.
\end{abstract}

This review presents a brief history of psychosurgery and summarizes the development of DBS for psychiatric disease, reviewing the available evidence for the current application of DBS for disorders of the mind.

http://thejns.org/doi/abs/10.3171/2015.3.FOCUS1546

KEY WORDS deep brain stimulation; psychiatric disease; psychosurgery

I N The Cure of Folly (c. 1475-1480), Hieronymous Bosch depicts what is touted as the first great artistic representation of neurological surgery. The surgeon, wearing what resembles a dunce cap, operates on the cranium of his hapless patient, who exhorts him to "dig out the stones of my folly." 243 Subsequent work in the 15 th and 16th centuries depicts surgeons cutting for stones in patients' heads to cure mental illness, but whether this represented contemporary mental health practices or merely commentary on the plight of patients at the mercy of medical malfeasants remains debatable. ${ }^{145,243}$ Nevertheless, this painting recapitulates the tensions underlying the increasing interest in neurosurgery for psychiatric illness today: the desire to affect human behavior and consciousness through physical action on the brain; the hope of treating or curing disabling illness by such action; the uncertainty regarding the underlying physiology, safety, and efficacy of such interventions; the willingness of the patient to undergo procedures with dubious benefit when no other effective treatment is available; and the popular perception of those performing and undergoing such procedures.

The cost of psychiatric illness justifies addressing these

ABBREVIATIONS ALIC = anterior limb of the internal capsule; $\mathrm{AN}=$ anorexia nervosa; $\mathrm{BDI}=$ Beck Depression Inventory; $\mathrm{BMI}=$ body mass index; $\mathrm{CM}-\mathrm{PF}=$ centromedianparafascicular thalamic complex; DBS = deep brain stimulation; ECT = electroconvulsive therapy; GAF = Global Assessment of Functioning; GP = globus pallidus; GPi = GP internus; HDRS = Hamilton Depression Rating Scale; ITP = inferior thalamic peduncle; LHb = lateral habenula; MADRS = Montgomery-Asberg Depression Rating Scale; MDD = major depressive disorder; MFB = medial forebrain bundle; NAcc = nucleus accumbens; $\mathrm{OCD}=$ obsessive-compulsive disorder; $\mathrm{PD}=\mathrm{Parkinson}$ disease; $\mathrm{pHr}=$ posterior hypothalamic region; PTSD = posttraumatic stress disorder; SCC = subcallosal cingulate cortex; STN = subthalamic nucleus; TRD = treatment-resistant depression; TS = Tourette syndrome; VC/VS = ventral capsule and ventral striatum; VTA = ventral tegmental area; YBOCS = Yale-Brown Obsessive-Compulsive Scale; YGTSS = Yale Global Tic Severity Score.

SUBMITTED February 1, 2015. ACCEPTED March 23, 2015.

INCLUDE WHEN CITING DOI: 10.3171/2015.3.FOCUS1546.

DISCLOSURE The authors report no conflict of interest concerning the materials or methods used in this study or the findings specified in this paper. 
difficult issues. Across the world, neuropsychiatric disease is the most important cause of disability, accounting for in excess of $37 \%$ of all healthy life-years lost to disability. ${ }^{167}$ In fact, depression is the single leading cause of disability in both males and females, ${ }^{167}$ affecting $10 \%-15 \%$ of the population..$^{10}$ Notably, between $50 \%$ and $66 \%$ of treated patients do not respond fully to medical therapy alone, requiring additional psychosocial interventions, and between $10 \%$ and $30 \%$ of patients are resistant to multiple classes of treatment. ${ }^{10}$ In the US, more than one-quarter of the population at large has a mood, anxiety, or substance abuse problem. ${ }^{131}$ Faced with this disease burden, enthusiasm for a surgical treatment for psychiatric disease is understandable - if the procedures are safe and effective.

With the increasing recognition of the burden of psychiatric disease there is a concomitant increase in interest in the development of safe and efficacious surgical treatment of that subset of patients who remain refractory to medical treatment. Psychosurgery has endured popular backlash after indiscriminate application in the face of dubious efficacy in the first half of the 20th century. Compared with the imprecise destructive procedures of that era, DBS has the advantages of being precisely targeted, relatively minimally invasive, essentially reversible and nondestructive, and adjustable with respect to stimulation parameters. This article examines the growing body of evidence for the application of DBS technology in the treatment of psychiatric disease (Fig. 1).

\section{A Brief History of Psychosurgery}

Evidence of successful cranial surgery in the form of trephination predates recorded history. ${ }^{12}$ Whether such procedures were performed in response to trauma, epilepsy, or mental illness is open to speculation..$^{63,239}$ This practice persisted into the Medieval and possibly the Renaissance periods. ${ }^{168}$

In the 19th century, the notion of functional localization in neuroanatomy was advanced by Franz Gall with the advent of phrenology. While ultimately discredited, this work formed the basis of the notion that discrete anatomical areas of the brain were responsible for various neurological functions. ${ }^{239}$ Physicians such as John Harlow, ${ }^{102}$ Pierre Paul Broca, ${ }^{37}$ and Carl Wernicke ${ }^{295}$ described the association of patterns of brain lesions and behavior, forming the backdrop against which the underlying assumptions of early psychosurgery developed: pathological mental states, being associated with particular loci of cortex, could be treated by the removal of such loci, alleviating the patient's condition.

This theory was first put in practice in 1888 by Gottlieb Burckhardt in Switzerland, who performed the procedure in and reported on a series of patients undergoing cortical extirpation for the treatment of "primäre Verrücktheit"-a clinical entity equivalent to schizophrenia-consisting of aggression, delusions, and auditory hallucinations. ${ }^{180} \mathrm{~Pa}-$ tients received bilateral topectomies in the frontal, temporal, and parietal lobes; he reported success in one-half of patients thus treated, but without mention of aphasia or motor side effects. These results were greeted with skepticism and some degree of hostility.
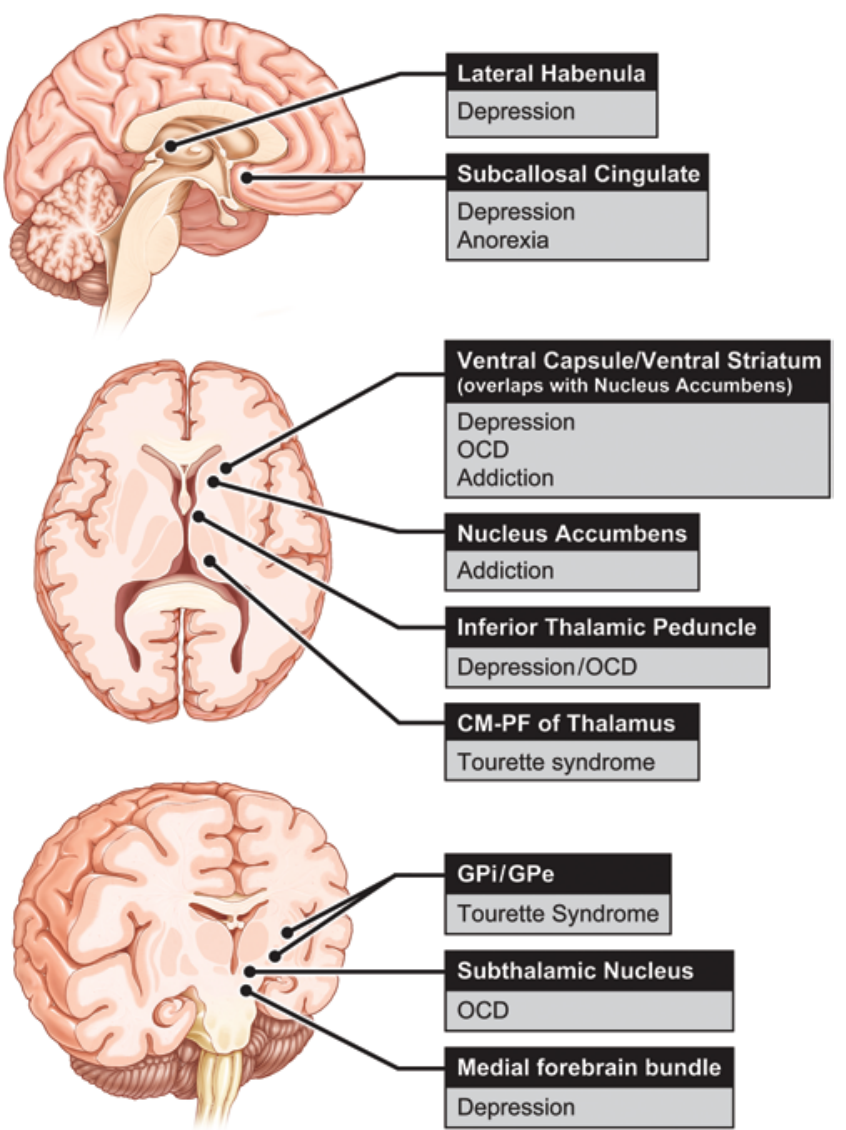

FIG. 1. Schematic showing locations of common targets of DBS for psychiatric disease, with indications, in parasagittal, axial, and coronal sections. GPe = GP externus. Copyright Andrew J. Rekito. Published with permission.

In 1935, John Fulton and Charles Jacobsen presented a study on the behavioral changes exhibited by primates after surgically created frontal lobe lesions. Bilateral resection of frontal association cortex was noted to blunt emotional responses.77 Six months later, Egas Moniz, a Portuguese neurologist, with the help of neurosurgeon Almeida Lima, began a clinical trial of prefrontal leukotomy for the treatment of anxiety, depression, and schizophrenia. ${ }^{197}$ Despite lukewarm clinical results, the procedure became popular. In the US, Walter Freeman and James Watts championed the procedure, developing tools such as the "precision leucotome" and tailoring the lesion location based on patient symptoms. ${ }^{239}$ By 1949 , more than 10,000 leukotomies had been performed in the US, ${ }^{298}$ rising to more than 60,000 by 1956.239

A major factor in the popularization of this procedure was the lack of alternative therapies for mental illness. Insulin coma therapy, metrazol shock therapy, and electroconvulsive therapy (ECT) were the major treatments for disabling mental illness in the early 1900s; "talking" therapies such as those endorsed by Sigmund Freud were beyond the ken of the more seriously ill. ${ }^{239,279}$ The burden of psychiatric illness in the 1930s and 1940s was tremendous, with nearly half a million Americans living in psychiatric institutions in 1937. ${ }^{187}$ Yet, as early as 1949, the year Moniz was awarded the Nobel Prize for his work 
on psychosurgery, skepticism regarding the efficacy and safety of the leukotomy procedure began to surface. ${ }^{91,106}$ Ultimately, it was not these concerns that led to the demise of the prefrontal leukotomy as accepted therapy, but rather the advent of chlorpromazine in 1953 that precipitated the decline in popularity of the frontal lobotomy. ${ }^{239}$ This decline was hastened by popular and cultural changes in the 1960 s, evidenced by the portrayal of psychosurgery in novels such as One Flew Over the Cuckoo's Nest, resulting in the banning of psychiatric neurosurgery in states such as California and Oregon.

Although the relatively nonspecific prefrontal leukotomy was discredited, important neuroanatomical work by James Papez and Paul Maclean paved the way for survival of psychiatric neurosurgery by elucidating of the structures of the limbic lobe and the connections between the frontal lobes and subcortical structures. ${ }^{173,218}$ Surgeons such as William Scoville and Geoffrey Knight developed and advocated more focal lesioning to avoid indiscriminate destruction of brain tissue. ${ }^{137}$ Additionally, the subsequent development of stereotactic techniques that allowed more precise, circumscribed lesions mitigated unwanted side effects of surgery. ${ }^{100,101,187}$ The anterior cingulotomy was described in 1952, ${ }^{297}$ and continues to be performed for obsessive-compulsive disorder (OCD), major depressive disorder (MDD), and bipolar disorder, with more than 1000 cases reported without a death. ${ }^{156,220}$ Subcaudate tractotomy was described in 1964 as a treatment for similar indications by disrupting the connections between the frontal lobe and amygdala; ${ }^{136}$ Lars Leksell and Jean Talairach described anterior capsulotomy for OCD;161,274 and the limbic leukotomy was reported in 1973, combining attributes of the subcaudate tractotomy and anterior cingulotomy. ${ }^{127}$ Treatment response rates for each of these procedures ranges from $30 \%$ to $70 \%$, with relatively minimal long-term side effects. ${ }^{160,220}$

Concurrently, organizations such as the International Society for Psychiatric Surgery (ISPS) were emphasizing the need for conscientious data reporting and multidisciplinary cooperation between neurosurgeons, neurologists, and psychiatrists. ${ }^{165}$ The National Commission for the Protection of Human Subjects of Biomedical and Behavioral Research established circumstances under which psychosurgical procedures could be appropriately performed; in 1980, the first Diagnostic and Statistical Manual of Mental Disorders (DSM) codified the diagnosis of psychiatric disorders. Thus, the foundation for the contemporary application of procedures such as cingulotomy was established. ${ }^{165,187,220}$

Common belief dictates that the use of long-term highfrequency stimulation of the brain was "invented" by Benabid in 1987 for the treatment of movement disorders. Certainly, this group was the first to study the therapeutic role of DBS systematically. However, the literature reveals that the use of long-term electrical stimulation at deep brain targets was explored as early as the $1950 \mathrm{~s} .{ }^{51}$ The reversibility of treatment effects was noted by Irving Cooper in the $1970 \mathrm{~s} .{ }^{241}$ The fact remains, however, that the safety and efficacy of DBS as a therapeutic modality was established by its use in the treatment of movement disorders. ${ }^{25,54}$

Several convergent lines of evidence were important for the redevelopment of DBS as viable for the treatment of psychiatric disease. Functional and anatomical studies have recharacterized many psychiatric diseases as dysregulation of brain networks rather than simply shortages or overabundances of specific neurotransmitters. Simultaneously, observations of affective changes in response to DBS in targets such as the subthalamic nucleus (STN) have provided evidence for the psychomodulatory effect of long-term stimulation of limbic networks. ${ }^{275}$ Initial attempts to treat OCD with DBS targeted one of the traditional surgical targets for ablation, the anterior limb of the internal capsule (ALIC). ${ }^{210}$ These studies have emphasized the interaction between basal ganglia, frontal cortex, and the limbic lobe, and have provided a physiological justification for several targets for neuromodulation.

For example, investigations into the mechanism of action of antidepressant medications revealed mediation of widespread but anatomically specific changes in brain metabolism corresponding to clinical response to treatment, providing potential targets for neuromodulation by DBS. ${ }^{28,189}$ Characterization of network changes via multiple modalities such as PET, fMRI, and diffusion tractography similarly elucidated possible sites for intervention in OCD. ${ }^{43,109,182,212,226}$ Metabolic and functional imaging studies demonstrate network abnormalities in patients with Tourette syndrome (TS), ${ }^{227}$ posttraumatic stress disorder (PTSD), ${ }^{112}$ addiction ${ }^{46}$ and obesity ${ }^{71,153}$ Trials investigating the modulation of these targets with DBS for the treatment of psychiatric disease have followed.

\section{Depression \\ Background}

Major depression is one of the most common psychiatric illnesses and, because of the high incidence, accounts for a relatively large loss of life and productivity. ${ }^{15,131,154}$ Many patients with MDD respond to pharmacotherapy and psychotherapy, but approximately $20 \%$ of patients continue to experience symptoms after years of maximal medical and psychiatric therapy. ${ }^{64,126,242}$ Advances in imaging technology have improved our understanding of the neurophysiological basis of depression, and we now know that specific brain regions and specific neural circuits are dysfunctional in severe depression. Areas such as the cingulate cortex, dorsomedial orbital cortex, and ventral striatum (VS) show pathological activity in depressive states, and this activity normalizes with treatment and resolution of depression. ${ }^{40,83,188}$ In cases of treatment-resistant depression (TRD), destructive neurosurgical interventions can be used on the dysfunctional areas. Destructive procedures such as cingulotomy, anterior capsulotomy, and limbic leukotomy help a subset of patients, but all treated patients risk long-term neurological deficiencies. ${ }^{90}$ In the past decade, DBS has arisen as a way to modulate the dysfunctional regions and circuits in a reversible, nondestructive fashion. Several different areas within the limbic lobe have been targeted, including subcallosal cingulate cortex (SCC), nucleus accumbens (NAcc), and the medial forebrain bundle (MFB). To date, the success rates of DBS have been commensurate with those of destructive procedures, but the major benefit is that DBS is adjustable 
and largely reversible. A summary of pertinent trials and results is presented in Table 1.

Response to stimulation is usually quantified with the Hamilton Depression Rating Scale (HDRS), although Global Assessment of Functioning (GAF), Beck Depression Inventory (BDI), and Montgomery-Asberg Depression Rating Scale (MADRS) are used as well. A "response" to therapy is commonly defined as a decrease of $50 \%$ or greater, and an HDRS score less than 8 is considered "remission." In general, patients eligible for DBS trials start with an HDRS score between 25 and 40, and will have exhausted all other treatments, including cognitive-behavioral therapy, pharmacotherapy, and ECT. Most patients in trials have had multiple episodes of major depression that last several years. In these severely affected patients, for many the response to DBS begins as soon as weeks after the start of stimulation and, for some, has been sustained for years. Once a response is achieved, it is usually sustained for as long as stimulation continues. Both battery depletion and accidental disconnections have resulted in rapid regression and even suicidal crises. ${ }^{108,169}$

In light of the promise of DBS and the early results from open-label trials, a number of groups are now moving forward with larger randomized and blinded trials to better establish the safety and efficacy of this treatment paradigm. Although a number of questions remain regarding the appropriate targeting and programming of DBS in the treatment of depression, the technique has clearly improved the lives of many patients.

\section{Subcallosal Cingulate Cortex}

Among the DBS targets for treatment of depression, the best studied is the SCC, also referred to as Brodmann area 25 (BA25) or subgenual cingulate $(\mathrm{Cg} 25)$. Increased activity in this region has been linked to depression, and normalization of activity correlates with clinical response to treatment..$^{83,189,200,209}$ The first trial stimulation of this region was introduced in $2005,{ }^{190}$ and since that time other independent groups have found a similar therapeutic response from DBS. ${ }^{108,194,230}$ Other than complications associated with device implantation, including surgical site pain and infection, few stimulation-related adverse effects have been reported. ${ }^{108,190,194}$ This population has a high risk for suicide and suicide attempts, and so should be monitored closely. ${ }^{169,190,194}$ Neuropsychological testing has shown no persistent cognitive impairment as a result of stimulation at this target. ${ }^{192}$

In a 2005 report on the initial group of 6 patients, some participants experienced intraoperative improvement in moods with electrode placement. Such an effect is similar to the microlesioning often seen in patients with Parkinson disease (PD), in whom placing the electrode leads to an immediate improvement in motor symptoms. ${ }^{42}$ At 6 and 12 months postimplantation, the response and remission rates were $60 \%$ and $35 \%$, respectively. ${ }^{190}$ In the following years another 14 patients were added to the cohort, and at the 3 - to 6-year follow-up points, among the 14 patients still being followed, the response rate was $64 \% .{ }^{170}$ During the follow-up period, 3 patients had died: 2 from suicide and 1 from colon cancer. ${ }^{129}$ Other reports show similar findings. A group in Spain implanted DBS electrodes in 8 patients with TRD, and the majority of patients showed significant improvement at 1 year, with $62.5 \%$ of patients responding and $50 \%$ in remission. ${ }^{231}$ A group in Germany implanted electrodes in Brodmann area 25 in 6 patients with TRD, and reported 2 patients (33\%) in remission by 9 months. ${ }^{194}$ In a US trial of 10 patients with MDD and 7 patients with bipolar II disorder, at 2 years postimplantation $65 \%$ of patients had a clinical response, and $41 \%$ of patients were in remission. ${ }^{108} \mathrm{~A}$ more intensive multisite

TABLE 1. Selected literature on DBS for depression

\begin{tabular}{|c|c|c|c|c|c|c|}
\hline Authors \& Year & $\begin{array}{l}\text { No. of } \\
\text { Pts }\end{array}$ & Study Type & Target & Results & $\begin{array}{l}\text { Outcome } \\
\text { Scale }\end{array}$ & Adverse Events \\
\hline $\begin{array}{l}\text { Mayberg et al., 2005; Lozano et al., } \\
\text { 2008; Kennedy et al., } 2011\end{array}$ & 20 & Case series & SCC & $64 \%$ response, $43 \%$ remission & HDRS & 2 suicides \\
\hline Puigdemont et al., 2015 & 5 & $\begin{array}{l}\text { Randomized, double-blind, } \\
\text { sham-controlled }\end{array}$ & SCC & $80 \%$ response & HDRS & \\
\hline Puigdemont et al., 2012 & 8 & Case series & SCC & $62 \%$ response, $50 \%$ remission & HDRS & 1 suicide attempt \\
\hline Merkl et al., 2013 & 6 & Randomized, double-blind & SCC & $33 \%$ response & HDRS & \\
\hline Holtzheimer et al., 2012 & 17 & Open label, single-blind & SCC & $65 \%$ response, $41 \%$ remission & HDRS & $\begin{array}{l}9 \text { relapses w/ battery } \\
\text { depletion }\end{array}$ \\
\hline Lozano et al., 2012 & 21 & Multisite case series & SCC & $29 \%$ response & HDRS & 1 suicide \\
\hline Malone et al., 2009 & 15 & Multisite case series & VC/VS & $53 \%$ response, $40 \%$ remission & HDRS & \\
\hline Dougherty et al., 2014 & 30 & $\begin{array}{l}\text { Randomized, double-blind, } \\
\text { sham-controlled, multi- } \\
\text { site }\end{array}$ & VC/VS & $\begin{array}{l}\text { 23\% response; no significant } \\
\text { difference btwn sham \& } \\
\text { control arms }\end{array}$ & MADRS & \\
\hline Bewernick et al., 2010, 2012 & 11 & Case series & NAcc & $45 \%$ response, $9 \%$ remission & HDRS & 1 suicide \\
\hline Schlaepfer \& Bewernick, 2013 & 7 & Case series & MFB & $\begin{array}{l}86 \% \text { response by MADRS; } 29 \% \\
\text { response by HDRS }\end{array}$ & $\begin{array}{r}\text { MADRS, } \\
\text { HDRS }\end{array}$ & \\
\hline Kiening \& Sartorius, 2013 & 1 & Case report & $\mathrm{LHb}$ & Remission & None & \\
\hline Jiménez et al., 2005 & 1 & Case report & ITP & Remission & HDRS & \\
\hline
\end{tabular}

Pts $=$ patients. 
trial across 3 hospitals in Canada reported a 57\% response rate at 1 month and $29 \%$ at 1 year, although the authors point out that a greater number of patients experienced clinical improvement. ${ }^{169}$

Multiple groups are moving toward formalized trials, although sham-treatment periods in crossover and blinded trials have been limited because of concerns for patient welfare. For example, in one trial a 24 -week sham-treatment period was stopped after 3 patients were recruited, because of a rapid regression to the depressive state with suicidal ideation. ${ }^{108}$ Small studies, such as a recent doubleblind, randomized, sham-controlled study in 5 patients, show definite response to DBS of the SCC in patients with TRD, with stimulation needed to maintain the response that was seen in 4 of 5 patients. ${ }^{231}$ Despite the promising results, a number of questions remain unanswered, including the optimal electrode placement, optimal stimulation parameters, and patient selection criteria. The initial stimulation target was the gray/white matter junction adjacent to Brodmann area 25, but subsequent analyses of sites of efficacious treatment have argued that the nearby site Brodmann area 24, the associated SCC white matter tracts, or slightly more ventral sites may be more efficacious targets. ${ }^{97,108,230,236}$ Likewise, stimulation parameters are usually chosen based on empirical trials or optimal stimulation parameters used for other diseases, such as with PD. ${ }^{94}$

The clinical outcome that should be optimized remains unclear: whether the immediate response to stimulation or the response after days or weeks. If a hyperacute response is seen in the operating room, more commonly the patient will improve over weeks to months. ${ }^{170,190}$ Conversely, all other antidepressant therapies reach their peak effect in weeks to months, so it is not unreasonable to expect that a similar time scale is necessary for DBS to reach its peak effect. ${ }^{83,189}$ Last, patient selection presents unique challenges in DBS for depression. Comorbidities such as anxiety and personality disorders are common in patients with MDD, and not all patients with TRD may have the same neurophysiological pathology susceptible to DBS in the SCC.

\section{Ventral Capsule and Ventral Striatum}

The ventral capsule and ventral striatum (VC/VS), also referred to as the ALIC, was initially a target for in the treatment of medically refractory OCD. ${ }^{164}$ The idea for treatment of depression with DBS in the VC/VS came from reports of stimulation for OCD, where patients' depression and anxiety simultaneously improved.$^{78,210}$ In an initial trial, 8 of 10 patients whose primary diagnosis of OCD had comorbid clinical depression, and from an average HDRS baseline of 21.1, by 36 months the average score had dropped to 15.4. More importantly, many patients had significant improvements in social functioning, including 6 who resumed work and/or school and 6 who had transitioned to independent living. During the course of the study, 6 patients had battery depletion or other unexpected interruption, which correlated with an acute return to depressed mood and a corresponding rise in HDRS from an average of 12.0 to 22.7. ${ }^{210,211}$

Although these improvements in mood could have been entirely secondary to change in circumstance from clinical improvement, evidence indicates that the neural pathology in OCD is concordant with that of depression. ${ }^{35,234,248}$ Since the initial reports, an open-label trial of VC/VS stimulation has been run with 15 patients. ${ }^{179} \mathrm{At}$ baseline, the patient cohort had an HDRS score of 33.1, which dropped to 17.5 at 6 months and to 14.3 at last follow-up. In looking at individual participants, 7 patients showed a response and 3 were in remission at 6 months postimplantation, and by the last follow-up 53.3\% of patients were maintaining a response to treatment and $40 \%$ were in remission. ${ }^{179}$ However, a larger, sham-controlled study of VC/VS stimulation did not show the same degree of positive results. ${ }^{57}$ Thirty patients with TRD were recruited in a multisite trial that started with a 16 -week period of either sham or active stimulation. Of those receiving active stimulation, 3 of 15 had a clinical response, but 2 of 15 had a clinical response from sham stimulation. The active-stimulation group did see a higher level of adverse effects from stimulation, including worsening depression, irritability, and mania. During the open-label phase, which included follow-up to a minimum of 24 months, only 6 of the 30 patients qualified as responders at 12 months, and that figure had only risen to 7 patients by 2 years.

Although these results appear discouraging, they should be examined in the context of other studies of DBS for TRD and the treatment of TRD in general, in that a $10 \%$ placebo effect is seen in surgery for depression. ${ }^{242}$ Reported surgery-related complications included a small asymptomatic hemorrhage, intraoperative seizure, lead revision, and wound infection..$^{57,89,179,211}$ Suicidality is also a major concern, with more than $10 \%$ of patients reported as attempting suicide in a larger study. ${ }^{57}$ Stimulationrelated adverse effects are seen most often with the ventral contacts closest to the VS, which are often the most efficacious for treatment as well. ${ }^{179}$ Physiological effects of stimulation include tachycardia, nausea, changes in respiratory rate, and sweating; behavioral or psychological adverse effects include mania, hypomania, anxiety, panic, fear, worsening depression, unpleasant tastes or smells, and facial motor tics..$^{89,179,215}$ In neuropsychological testing, 1 study reported a statistically significant but clinically questionable decline in some areas of cognitive performance, whereas other trials have noted an improvement in recall. ${ }^{57,89,179}$

\section{Nucleus Accumbens}

The NAcc is a group of neurons located in the VS that has been closely linked to motivation and reward-seeking behavior. ${ }^{6,48}$ In humans, increased activity in this region is seen in association with reward-seeking behaviors: monetary reward, drugs of abuse, pleasurable music, and viewing attractive faces; $9,31,34,58,122,139$ decreased activity and dysfunction is seen in patients with depression, and so presents a reasonable target for focal neuromodulation. ${ }^{62,184,278}$ To date, only 1 group has focused on DBS of the NAcc for depression, although it should be noted that the electrode placement described in stimulation of $\mathrm{VC} /$ VS overlaps more ventral locations used for stimulation of the NAcc. ${ }^{28,179}$

The initial trial of stimulation of the NAcc for TRD in- 
volved 3 patients with severe depression. Each was refractory to repeated trials of psychotherapy, pharmacotherapy, and ECT. At the initiation of the trial, the average HDRS score for this group of patients was 33.7. Bilateral electrodes were placed in the VS, with the 2 deepest contracts targeted to the core and shell regions of the NAcc. The authors noted immediate changes in affect and improvement in mood and HDRS scores over the next several weeks, although for 1 patient the results were not sustained. After 1 week, the average HDRS score dropped to 19.7, and during a blinded period of sham stimulation, increased back to 29.3. The patients noted no euphoria from stimulation of the NAcc, and no adverse effects related to stimulation were noted. ${ }^{252}$

Based on these results, the authors initiated a larger, open-label trial of stimulation to the NAcc with first 10 and then 11 patients. The trial was initiated as a blinded, sham-controlled study, but the study design was changed after sudden resurgence of depressive symptoms during sham stimulation, as seen with other trials of DBS for depression. ${ }^{108}$ This cohort of patients had similar characteristics, with the current depressive episode lasting an average of 10.8 years and an HDRS score of 32.5. The DBS electrodes were targeted as before to the core and shell subregions of the NAcc, and after 12 months of stimulation 5 patients were classified as responders and 3 patients were in remission. The patients who showed improvement with stimulation also had a reduction in anxiety, as measured with the Hamilton Anxiety Rating Scale. ${ }^{27,28}$ Comparing baseline to poststimulation PET imaging, patients showed decreased metabolic activity in the prefrontal cortex, subgenual cingulate cortex, and the thalamus, and they had increased activity in the precentral gyrus, which were consistent with changes seen in DBS of the SCC for depression. ${ }^{190}$ Stimulation parameters were adjusted no more quickly than every 4 weeks, to account for a possible longer latency of antidepressant effect.

Although the patients did show acute improvement with stimulation, the acute response was not necessarily indicative of a long-term response. ${ }^{27}$ Adverse effects from stimulation included flushing, anxiety, sweating, hypomania, agitation, and psychosis, with greater tension and restlessness noted at higher frequencies or pulse widths. Of note, one patient attempted suicide and another patient successfully committed suicide..$^{27,28}$ With neuropsychiatric testing, the cohort of patients experienced a normalization of many of the previously below-average values, including attention, learning, memory, executive function, visual perception, and cognitive functioning. Deficiencies in these areas are often noted with depression, and the improvement may be marker of the resolving depression rather than an independent nootropic effect of stimulation in the NAcc. ${ }^{92}$

\section{Medial Forebrain Bundle}

The success of DBS for TRD from not one but multiple different areas of stimulation has increased interest in stimulation of other neural pathways for a faster or more efficacious effect. The MFB is a white matter tract that mediates connectivity between many important cortical and subcortical regions, including the ventral tegmental area (VTA), NAcc, medial and lateral hypothalamus, lat- eral and medial preoptic regions, and the bed nucleus of the stria terminalis. ${ }^{300,308}$

Based on the connection between the VTA and NAcc from the superolateral MFB and the limited success of NAcc stimulation for depression, ${ }^{27,28}$ it was hypothesized that DBS of the superolateral MFB may be an equal or better target for treating depression. ${ }^{44,45}$ An open-label trial of DBS for TRD targeted the superolateral MFB in 7 patients, with stimulation sites selected based on diffusion tensor imaging and tractography. ${ }^{251}$ Intraoperative stimulation produced acute and immediate effects, with the patients increasing visual and social contact with the clinical team. Similar responses were seen in the days and weeks after induction of stimulation; at 2 days after the start of stimulation, 6 of 7 patients were classified as responders, although this value dropped to 4 of 7 by 1 week. In this case, though, the authors defined clinical response and remission in terms of the MADRS rather than the more commonly used HDRS. Using the HDRS, only 2 of 7 patients would be considered to be responding, although both would also be considered in remission. This raises the question of whether MADRS or HDRS better represents the clinical improvement from DBS. Adverse effects of stimulation were predominantly oculomotor symptoms, including blurred vision, strabismus, and double vision.

\section{Lateral Habenula and Inferior Thalamic Peduncle}

Several smaller studies and case reports have demonstrated antidepressive effects of DBS in other sites in the brain, including the lateral habenula ( $\mathrm{LHb}$ ), inferior thalamic peduncle (ITP), and globus pallidus (GP). The ITP is a discrete fiber bundle connecting the nonspecific thalamic nuclei (midline, intralaminar, and paralaminar) to the orbitofrontal cortex, and the ITP has been implicated in arousal, learning, and attention, and also in depression: ${ }^{115,175,250,288}$ lesioning of this area and nearby ones has been used in humans to control TRD, and notably the subcaudate tractotomy, which includes the ITP, improves symptoms in depressive patients. ${ }^{134,287}$

Bilateral DBS of the ITP was first demonstrated in 2005 in a case study of a woman with severe, treatment-refractory MDD comorbid with borderline personality disorder and bulimia. ${ }^{119}$ The patient had a baseline HDRS score of 33 , and after starting stimulation this score dropped, corresponding to a rise in her GAF from 20 to 90 . In the initial year after implantation, the patient experienced a moderate return of depressive symptoms when the stimulator was turned off for a double-blind testing period. After 3 years of stimulation, the patient chose to have the device explanted and did not have a relapse in depressive symptoms for the remainder of her follow-up. ${ }^{18}$ Side effects from stimulation of the ITP included anxiety, nystagmus, dyspnea, sweating, and tachycardia. Limited improvement has been noted in some areas of memory and cognitive function and no decline in function was noted on neuropsychological testing. ${ }^{118,119}$

Stimulation of the LHb for TRD has been documented in a brief case report. The LHb has extensive connections to serotonergic, noradrenergic, and dopaminergic nuclei; hyperactivity in the $\mathrm{LHb}$ is seen in animal models of depression, ${ }^{264}$ and similar metabolic overactivity is seen in 
the area in patients with depression. ${ }^{232}$ Based on animal and human studies, Sartorius and colleagues implanted bilateral electrodes in the afferent fiber bundle approaching the LHb in 2 patients with TRD. ${ }^{133,246}$ The first patient's HDRS score decreased from 45 at baseline to less than 5 following stimulation, and the second patient was reported to have a greater than $50 \%$ decrease in HDRS. Interruption of the stimulation resulted in rapid relapse in depressive symptoms in both patients, which slowly abated after resumption of stimulation. The authors did not report the full range of stimulation parameters, but the first patient did require an increase in voltage from $5 \mathrm{~V}$ to $10.5 \mathrm{~V}$ to achieve full remission, which suggests that frequent battery replacements may be a complicating factor in longterm treatment. No adverse effects were reported.

\section{Ethical Considerations}

Limited data exist on the use of mood-enhancing stimulation in humans, and even less for areas known to be involved in motivation. In rats and other animal models, subjects will work for VTA self-stimulation in much the same way as for drugs of abuse such as cocaine. ${ }^{26}$ The purposeful stimulation of cingulum, NAcc, and associated fiber tracts in humans may be justified as an experimental treatment for severe, chronic, and disabling depression, but this is nevertheless an area rife with potential ethical concerns. If DBS is approved for TRD, a concern would be the perceived overuse of the technique in a young and otherwise healthy population, who are already a substantial portion of the population on antidepressants. Another issue of consideration is the potential hedonic effect of stimulation. In animals, stimulation of the some of the same target areas used for TRD can produce behavioral effects similar to that of drugs of abuse; clinicians must be aware of the potential for abuse. Most medical systems use rigorous controls intended to prevent the misuse of this technology, but some countries may not be as closely monitored. There rises the potential for unorthodox, unethical, or abusive applications.

Steps have been taken to address the considerable ethical dilemmas involved in stimulation of the limbic system. Multiple authors have required consent from not just the patients, but also one or more caregivers, and have added a mandatory waiting period before consideration of DBS. ${ }^{27}$ Guidelines are being established for use of stimulation for psychiatric indications, and these are all steps in the right direction. ${ }^{253}$ Before launching into greater use, the psychiatric and neurosurgical communities must spend additional time in open public discussion of the ethics, applications, and ramifications of the technique. Otherwise, the danger exists of repeating the events of the last century, when overuse and misuse of neurosurgery for psychiatric indications led to public backlash and the ban of such techniques in certain states (e.g., Oregon and California).

\section{Obsessive-Compulsive Disorder Background}

Obsessive-compulsive disorder is a disabling psychiatric disease defined by repetitive, intrusive, and persistent thoughts combined with excessive and repetitive ritualistic behaviors. It affects as much as $1 \%-2 \%$ of the general population and, because of the high prevalence and relatively high suicide rate, is a leading cause of disability. ${ }^{24,29,107,217}$ The majority of patients affected with OCD will improve with treatment, including pharmacotherapy (selective serotonin reuptake inhibitors, neuroleptics, and benzodiazepines) and cognitive-behavioral therapy, but as many of $10 \%$ of patients do not respond to these treatments. ${ }^{32,52}$ For these patients with treatment-refractory illness, a number of surgical and ablative options are available. Anterior capsulotomy and limbic leukotomy typically have a 50\%$60 \%$ success rate, and the less frequently used subcaudate tractotomy and cingulotomy have slightly lower response rates. ${ }^{22,82,116}$

Early attempts with DBS addressed the same targets used for ablation, specifically the ALIC. . $^{14210,211}$ The patients in these preliminary studies were all disabled from severe OCD that had lasted for years or decades, were unresponsive to multiple and maximal pharmacological trials (including augmentation with clomipramine and a mood stabilizer such as lithium), and had little improvement from cognitive-behavioral therapy. Following preliminary trials with ALIC, the percent of patients responding improved as the target migrated slightly from the ALIC toward the $\mathrm{VC}$ / VS and NAcc. ${ }^{88}$ Trials of DBS for OCD had similarly positive results with stimulation to the STN, ventral caudate, and ITP. Results of some of the more pertinent studies are summarized in Table 2.

The success of OCD treatment with stimulation at several different sites contributes to the hypothesis that the disease is a result of dysfunction in an entire corticostriatothalamocortical circuit, rather than a single site..$^{93,249,296}$ Multiple studies of patients with OCD have most consistently noted hyperactivity in the orbitofrontal cortex, anterior cingulate cortex, and VS, but other metabolic abnormalities are seen in the amygdala, thalamus, cerebellum, prefrontal cortex, motor cortex, and parietal cortex. ${ }^{233,272,283}$ Similar to capsulotomy, DBS normalizes the hyperactivity in the orbitofrontal cortex, the VS, and the amygdala, and clinical improvement correlates with the decrease in metabolism in VS and other hyperactive regions. ${ }^{88,211,283}$

Treatment-based improvements in OCD symptoms are quantified with the Yale-Brown Obsessive-Compulsive Scale (YBOCS), which has 20 points for obsessive symptoms and 20 points for compulsive symptoms, for a total score out of a possible 40 points. ${ }^{86}$ Successful treatment of OCD is typically defined as a $35 \%$ reduction in the YBOCS score from baseline. Anterior capsulotomy, for instance, achieved a response in roughly half of patients. ${ }^{196}$ Early experiments with DBS for OCD had responses in slightly less than half of patients, but with improved understanding of the circuit and targeting, approximately $60 \%$ of patients who receive DBS now respond to therapy, with a subset of those achieving minimal symptoms and YBOCS scores of less than 10. In a review of the literature on DBS for refractory OCD, the Congress of Neurological Surgeons found sufficient evidence to recommend the use of DBS for treatment-refractory OCD. ${ }^{98}$ This procedure has been approved for treatment of OCD in Europe, and in the US a humanitarian device exemption was granted for the use of DBS in refractory OCD. It is important to keep 
TABLE 2. Selected studies of DBS for OCD

\begin{tabular}{|c|c|c|c|c|c|}
\hline Authors \& Year & $\begin{array}{l}\text { No. of } \\
\text { Pts }\end{array}$ & Study Type & Target & Outcome & Rating Scale \\
\hline Sturm et al., 2003 & 4 & Case series & NAcc & Near total response in 3 of 4 pts & \\
\hline Mallet et al., 2008 & 8 & $\begin{array}{l}\text { Randomized, cross-over, double-blind, } \\
\text { multisite }\end{array}$ & STN & $\begin{array}{l}\text { Mean } 32 \% \text { reduction in symptom severity; } 30 \% \\
\text { increase in global function }\end{array}$ & YBOCS, GAF \\
\hline Huff et al., 2010 & 10 & $\begin{array}{l}\text { Randomized, cross-over, double-blind, } \\
\text { sham-controlled }\end{array}$ & NAcc & $25 \%$ reduction in symptom severity in $50 \%$ of pts & YBOCS \\
\hline Denys et al., 2010 & 16 & $\begin{array}{l}\text { Open label; randomized, cross-over, } \\
\text { double-blind, sham-controlled; then } \\
\text { open label }\end{array}$ & NAcc & $\begin{array}{l}\text { Mean reduction of } 46 \% \text { during open phase; } 25 \% \\
\text { reduction in symptom severity over sham } \\
\text { stimulation }\end{array}$ & YBOCS \\
\hline Greenberg et al., 2010 & 26 & Case series & VC/VS & $\begin{array}{l}73 \% \text { of pts responding } w />25 \% \text { decrease in sever- } \\
\text { ity }\end{array}$ & YBOCS \\
\hline Jiménez et al., 2013 & 6 & Case series & ITP & $\begin{array}{l}\text { Mean reduction of severity score by } 51 \% \text {; functional } \\
\text { score increased by average of } 68 \%\end{array}$ & YBOCS, GAF \\
\hline
\end{tabular}

in mind that a humanitarian device exemption is granted as a way to facilitate further research, but does not equate with FDA approval, and concerns have been expressed about the possible misuse of this exemption. ${ }^{67}$ Any institution that wishes to use the treatment requires institutional review board approval, and all patients must indicate additional consent acknowledging that DBS for OCD is an experimental therapy without established efficacy.

\section{Anterior Limb of the Internal Capsule, VC/VS}

The ALIC was previously used in the treatment of refractory OCD as a target for capsulotomy or Gamma Knife ablation. The first case series of DBS for OCD aimed for the same region, and reported improvement in 3 of 4 patients, although the improvement was not quantified. ${ }^{210}$ In a follow-up report, 2 additional patients had been added to the cohort, and of the 6 patients, 4 of them responded to the treatment-they had a decrease in YBOCS greater than $35 \% .^{211}$ As has been seen with several trials of DBS for depression, the sham phase of the study had to be stopped early because of concerns for patient welfare with rapid regression of OCD and depressive symptoms. Two larger follow-up studies from independent institutes showed better numbers of patients responding. A combined study from Butler Hospital and Cleveland Clinic presented longterm data in 10 patients with severe, chronic OCD. ${ }^{89}$ In this open-label study, the authors found that of the 8 patients followed to 36 months, 4 showed a clinical response, 2 other patients showed subthreshold response, and 5 of these patients were able to transition to independent living. A study at the University of Florida used a doubleblind, staggered-onset design to compare sham versus active stimulation. Of the 6 patients who received implanted electrodes, 4 were classified as responders, and the other 2 "nonresponding" patients requested to keep the system in place because of a perceived benefit. ${ }^{215} \mathrm{~A}$ recent small case series from Korea targeted the VC/VS with similar results; at 2 years postimplantation, 4 of 4 patients were classified as responders and 2 of 4 patients were in remission. ${ }^{240}$

To overcome the limitations from relatively small numbers of patients, a meta-analysis used the data from these first 3 independent studies to better show the trends in im- provement after treatment ${ }^{88}$ From the combined patient data, the 26 patients had a baseline YBOCS score of 34, which dropped to 21 after 3 months of treatment and to 20.9 at 36 months of treatment. On the whole, these patients showed a clinical improvement in social functioning, with a pre- and posttreatment GAF of $34.8 \%$ and $59 \%$, respectively. On the individual level, $61.5 \%$ of patients were responders by the last follow-up, and an additional $11.5 \%$ of patients had an improvement of at least a $25 \%$ decrease in YBOCS scores. From this meta-analysis, a trend in targeting was noted to correspond with improvement in patient outcomes. Patients appeared to have better outcomes as placements moved posterior and ventrally, and the stimulation settings almost always involved the more ventral leads, which are directly in or at the border of the NAcc. To reflect the change in targeting, this placement has been referred to as the VC/VS. One additional advantage of targeting this region has been similar clinical response with lower voltages and pulse widths, and thus longer times between battery changes.

Targeting VC/VS appears to improve outcomes, but a second part of the equation, the optimal stimulation parameters, remains an open question. Most studies have started with commonly used stimulation parameters and explored variations in frequency, pulse width, voltage, and contact combinations. No clear combination of settings has emerged as most efficacious, except that responses to stimulation almost always involve contact 0 or contact 1 (typically placed in or at the boundary of the NAcc). However, the improvement in functioning appears to occur over several weeks to months, so the correspondence (or lack thereof) between acute response and long-term improvement remains debated. One commonly noted response during the stimulation test has been the presence of acute mood improvement and a smile contralateral to stimulation, which appears to be predictive of long-term response. ${ }^{85,99,213}$ Contralateral smile is typically seen with stimulation in the deepest contacts, as are other adverse or unexpected effects on mood. Adverse effects are commonly seen at higher amplitude, larger pulse widths, or more ventral stimulation contacts, and the range of effects on mood include euphoria, giddiness, anxiety, panic, fear, 
and acutely worsening depression. More severe adverse effects include occasional reports of hypomania and at least 1 case of mania that required hospitalization. ${ }^{85,99,215,260}$

In patients with treatment-refractory OCD, a strong comorbidity exists with MDD, but whether the improvement in mood is a function of the stimulation or secondary to the improvement in primary OCD symptoms remains unclear; antidepressant effects have been seen independent of improvement in OCD function. However, suicidality and suicidal ideation have been seen with sudden DBS stops or battery depletion in patients treated for OCD or depression. ${ }^{1,85}$ Indeed, blinded studies on the effects of DBS have been limited because of concerns of worsening mood when attempting cross-over design. Despite the range of acute mood-related adverse effects, no consistent negative effects on cognitive or executive function have been reported from long-term stimulation. ${ }^{78,85,89,215}$ Non-moodrelated adverse effects from stimulation include elevation of heart rate, flushing, seizure, and perception of heat. ${ }^{85,215}$ Surgical complications and adverse effects reported are typical for DBS placement, including infection, lead revision, headache, surgical site pain, and rare intraparenchymal hemorrhage. ${ }^{88}$

\section{Nucleus Accumbens}

The NAcc is a discrete site in the VS that has been extensively tied to motivation and learning. The site is notable for its connections to other important limbic and motor regions, with efferent projections to the pallidum, striatum, thalamus, prefrontal cortex, and anterior cingulate cortex. The NAcc is best recognized because of the dopamine-containing projection from the VTA and the high concentration of D1- and D3-dopamine receptors in the NAcc. ${ }^{95,103}$ In studies conducted with animals, electrical stimulation of either the VTA or the NAcc is sufficient to affect motivational behavior, and animals will perform tasks for self-stimulation similar to what is seen with selfadministration of drugs of abuse. ${ }^{299}$ Dysfunction of the VS is seen with OCD, and DBS for treatment-refractory OCD has gradually migrated to targets with significant overlap with the NAcc. Indeed, if an in-depth anatomical comparison is made between stimulation aimed at the VC/VS and at the NAcc, few differences can be seen in actual areas of stimulation. ${ }^{30}$ However, the trajectories used and the contact placements do differ in some cases, so the NAcc will be discussed separately here. . $^{6,53}$

The first reported cases of DBS specifically targeted to the NAcc for OCD were initially focused on unilateral stimulation. ${ }^{271}$ The authors implanted electrodes bilaterally in 1 patient, but found that right-sided NAcc stimulation was as efficacious as bilateral stimulation, so for the following 3 patients they implanted unilaterally. Of these patients, 3 of 4 had reported resolution of OCD and anxiety by 24-30 months; the fourth patient had no benefit, which was attributed to a caudally and ventrally misplaced electrode. The authors did not quantify the degree of improvement, but did note that battery depletion led to rapid relapse of depressive symptoms, which was promptly resolved with replacement. A follow-up study in which unilateral implantation in the NAcc was used and a 3-month double-blind comparison found some improvement in patient outcomes, but the clinical response was less than had been observed with other similar placements. Specifically, at 1 year only 1 patient qualified as responding to treatment, with a YBOCS score decrease greater than $35 \%$, although 4 other patients had a decrease between $25 \%$ and $35 \%$. During the cross-over period, these patients showed a moderate but significant decrease between baseline and stimulation, but no statistical difference was found between the stimulation and sham. ${ }^{111}$ Despite the moderate improvements in OCD symptomatology, a significant improvement was seen in depressive symptoms, as measured with the BDI. In light of these modest gains, a systematic review by the American Society for Stereotactic and Functional Neurosurgery and the Congress of Neurological Surgeons found insufficient evidence to recommend unilateral DBS for OCD. ${ }^{98}$

Another study was published the same year that targeted the NAcc with bilateral implantation, and the authors reported that 9 of 16 patients responded with a YBOCS score decrease greater than $35 \%$, and 3 others had a decrease greater than $20 \%$ but less than $35 \%$. ${ }^{53}$ The doubleblind comparison had to be cut from 3 months to 2 weeks due to concerns for patient welfare and depressive relapse, and even then 2 patients refused to participate for fear of losing improvements. In the 2 -week cross-over doubleblind comparison, the authors found a significant difference (8.8 points) between sham and treatment conditions on the YBOCS, indicating clinical improvement from stimulation. The difference between these 2 studies may have been placement; in their work, Denys et al. noted that they specifically aimed to stimulate the NAcc at the border of the internal capsule and the bed nucleus of stria terminalis. ${ }^{53,111}$ Stimulation of the stria terminalis for OCD has not been extensively studied, but in a limited case series it was found to be comparably efficacious to NAcc stimulation. ${ }^{113}$ The specific target remains unclear, though, with another group targeting the junction between the NAcc and the caudate nucleus. These authors argue that the improvement in compulsive symptoms is actually secondary to caudate stimulation, whereas NAcc stimulation primarily mitigates the depressive symptoms. ${ }^{16,17,93}$ The data for this argument are based on small case studies, but many studies with ventral striatal stimulation note a consistent improvement in depressive symptoms that precedes the improvement in OCD symptoms, and stimulation-induced improvement in depression has occurred without improvement of obsessive and/or compulsive symptoms..$^{53}$

The adverse effects noted with implantation and stimulation are comparable to those seen with ALIC and VC/ VS. Surgical site infections, pain, and headache are seen occasionally, and intraoperative and postoperative stimulation can elicit physiological and mood changes. The most common side effect of NAcc stimulation appears to be elevation of mood and hypomania, although subjective reports of word-finding difficulty and forgetfulness are also noted. ${ }^{53,111}$ Anxiety, agitation, and drowsiness were occasionally noted, and 1 patient had suicidal ideation, although the timing was inconsistent with changes in stimulation settings. ${ }^{111}$

\section{Subthalamic Nucleus}

Interest in stimulation of the STN for OCD grew after 
multiple case reports were published describing incidental OCD symptom relief following DBS implantation. The STN is a common target for the motor dysfunction seen in $\mathrm{PD}$, but the area is involved in not just motor control, but also has cognitive and emotional functions. Based on cortical inputs, the region can be roughly subdivided into motor, associative, and limbic regions, with the anteromedial and ventromedial sections receiving more input from the limbic and associative areas, respectively. ${ }^{124,219}$ Stimulation of STN can result in reproducible alterations in mood, ${ }^{144,178}$ and recordings from the limbic and associative areas of the STN have revealed abnormalities in neuronal activity unique to OCD. ${ }^{223,293}$ Others have hypothesized that the STN is involved in integration of motor with limbic and associative functions, such as regulating impulse control and stop behaviors. ${ }^{19,61}$ Stimulation of the STN in humans has been reported to modulate other impulsive and compulsive behaviors, such as gambling, as well as resolving OCD personality traits. ${ }^{11,18}$

The first published case of STN stimulation alleviating symptoms in a patient with a formal diagnosis of OCD appeared in 2002. ${ }^{176}$ Two patients with both PD and OCD had received standard bilateral STN implantation for PD, but with stimulation onset both patients experienced notable relief from OCD symptoms within 1 week. The changes in obsessions and compulsive behaviors appeared to be independent of the motor function; one patient had a large improvement in motor symptoms, whereas the other had relatively little improvement. When the effect on OCD symptoms was quantified, it was found that the patients had an $81 \%$ and an $83 \%$ decrease in YBOCS scores, corresponding to remission of their OCD. When the stimulation sites were examined, it was found that the active contacts were slightly anteromedial to the usual placement. ${ }^{178} \mathrm{~A}$ second patient was also reported to have similar improvement in OCD symptoms with stimulation at slightly more medial and anterior contacts than are usually targeted. In this case, at 1-year follow-up, the patient had a decrease in YBOCS score from a baseline of 32 to a poststimulation score of $1{ }^{69}$

Following these positive reports, a thorough, doubleblind, cross-over study on the therapeutic effects of DBS of the STN on OCD was performed. ${ }^{177}$ The authors recruited patients without PD but with a primary diagnosis of severe, chronic OCD who had not achieved relief from multiple trials of pharmacotherapy and cognitive-behavioral therapy. All received bilateral lead placement in the STN, with the target being $1 \mathrm{~mm}$ medial and $2 \mathrm{~mm}$ anterior to that typically used in PD. After a period of stimulation tuning, the patients were randomized to either a sham period or a stimulation period. During the 3-month trial period, the average YBOCS score for stimulation was 19 \pm 8 , whereas the score for patients receiving sham treatment was $28 \pm 7$. The scores for GAF were similarly indicative of a therapeutic effect, with an average score on stimulation of $56 \pm 14$ versus $43 \pm 8$ with sham treatment. On an individual level, $75 \%$ of patients showed a clinical response to stimulation.

Analysis of the therapeutic sites for stimulation found that the majority were in the anteromedial STN, and a much lower minority were in the zona incerta and internal capsule. ${ }^{177}$ The rate of surgery-related adverse events was similar to that seen with lead placement for PD: 1 hemorrhage that resulted in a minor but permanent palsy, and 2 infections that required explanting at least a portion of the system. ${ }^{143}$ Stimulation-related adverse events were largely limited to transient motor or mood dysfunction that resolved with changes in stimulation parameters. Despite the positive results from this study, the mechanism of action by which stimulation in the STN improves OCD symptoms remains unclear. On functional imaging, the STN does not display unusual activity or metabolic changes in conjunction with OCD. Microelectrode recordings from the STN in patients with OCD have revealed bursting activity similar to that seen with PD, but the significance of this finding remains uncertain, because little is known about firing patterns in STN in healthy humans. ${ }^{223,293}$

\section{Inferior Thalamic Peduncle}

The ITP is of interest for OCD because it connects the nonspecific thalamic nuclei with the orbitofrontal cortex, a region that is consistently hyperactive in patients with OCD. ${ }^{115,175,250,267}$ Attempts have been made to regulate orbitofrontal hyperactivity through lesioning of the ITP via subcaudate tractotomy, with some success. ${ }^{262}$ The ITP has possible advantages over other current targets for DBS; it is anatomically and functionally distinct from the surrounding tissue, which may lower rates of misplacement and stimulation-induced adverse effects.

Six patients with treatment-refractory OCD received bilateral lead implants in the ITP and were followed for 1-4 years. ${ }^{118,120}$ Stimulation parameters were similar to those used in most other applications of DBS, with a frequency of $130 \mathrm{~Hz}$, pulse width of $450 \mu \mathrm{sec}$, and variable voltage and electrode contacts. The patients had a mean baseline YBOCS score of 35, which decreased to 17.5 with stimulation at 1 year. On the individual level, at 1 year all patients achieved a response, defined as a greater than $35 \%$ decrease in YBOCS score. The GAF scores were reported for 5 patients, and from a baseline of $20 \%, 5$ patients eventually achieved a GAF of $60 \%$ or greater, with 2 patients as high as $80 \%$ (independent living). Battery depletion or dysfunction correlated with a rapid relapse in symptoms. No consistent detrimental effects were seen in neuropsychiatric testing, and no adverse effects were noted from target stimulation. Side effects of stimulation outside of the target included transient confusion, tachycardia, and hypertension. This cohort of patients had a relatively high number who had substance abuse comorbidities, and the trial was complicated by a death from cocaine overdose in 1 patient. In the patients with substance abuse comorbidities, stimulation did not appear to relieve or worsen their substance abuse, which is an open topic of interest with other DBS targets for OCD such as the NAcc. ${ }^{120}$

\section{Anorexia Nervosa}

Anorexia nervosa (AN) will affect as many of $2 \%$ women in their lifetime, and is one of the most difficult psychiatric diseases to treat. ${ }^{105}$ Acute treatment of AN focuses on medical stabilization of the cardiac, neurological, and musculoskeletal complications from prolonged starvation, and longer-term care goals are aimed at changing 
behaviors. Selective serotonin reuptake inhibitors, neuroleptics, and cognitive-behavioral therapy are the primary treatment modalities, but despite optimal treatment, relapses are common. As many as $30 \%$ of patients show little or no improvement with treatment, and long-term mortality is as high as $15 \%$ from suicide or medical complications of starvation. ${ }^{311}$ In recent years, unique neural changes underlying AN have been delineated, suggesting that a distinct anatomical or physiological neuropathology is involved. For end-stage cases of AN, limbic leukotomy, thalamotomy, and anterior capsulotomy lead to improvement in some patients, but use of these procedures is limited by the potential for permanent side effects. ${ }^{23,198,309}$ In recent years a renewed interest in neurosurgical treatment of AN has arisen due to the success of DBS for OCD, because of the high comorbidity and similarity in patterns of behavior. ${ }^{13,283}$

Exploration of DBS for anorexia is still in the earliest stages, with only a few reported case studies and small trials, and no standardized criteria for treatment have yet been established. Sites for stimulation have focused on the same targets used for depression and OCD, namely the NAcc, VC/VS, and SCC. Results are summarized in Table 3. In a single case report of stimulation in VC/VS for $\mathrm{AN}$, the site of active stimulation was actually in the ventral caudate, but the patient was reported to have improved. ${ }^{191}$ In 2 patients in whom electrodes were implanted in the NAcc, stimulation was correlated with improvement in weight and attitudes toward food. The 2 patients had baseline body mass indexes (BMIs) of 13.3 and 12.9, and at 1-year follow-up their BMIs were increased to 18 in one and 20.8 in the other. ${ }^{292}$ These 2 patients also had normalization of core temperature and heart rate, and decreased anxiety and depressive symptoms. A slightly larger study from China on stimulation in the NAcc focused on DBS in the NAcc in 4 female patients, who experienced an increase in average BMI from 11.9 to 19.6 in a multiyear follow-up. ${ }^{303}$ Despite the fact that all patients had the system explanted, they all were reported to have reached remission. However, these results should be approached with caution because the patients were all adolescents (16-17 years old), and none had a history of AN longer than 2.5 years. Given the natural history of this disease (three-quarters of adolescent $\mathrm{AN}$ resolves with standard treatment after 4-5 years), questions arise regarding the completeness of medical and psychiatric treatment before transitioning to neurosurgery. ${ }^{269}$

The second target that has been tested for DBS in AN has been the SCC. In a case report on DBS in the SCC, a patient with AN had a clear correlation between her depressive episodes and eating disorder relapses. ${ }^{114}$ The pa- tient presented with a BMI of 19.7, and in the 2 years after electrode implantation in the SCC she had no reliable improvement in BMI, but did have a significant improvement in approach toward food, as measured with the Eating Attitudes Test (EAT_26). ${ }^{80}$ A second, larger study on AN and DBS involved bilateral SCC electrode implantation in 6 patients with long-standing, treatment-refractory AN. ${ }^{166} \mathrm{At}$ 9-month follow-up, 3 of 6 patients were above their historical baseline BMI, but only 2 of those patients achieved a BMI greater than 18.5. Four of the patients had comorbid depression, and despite the moderate gains with their AN, these patients saw significant improvements in mood and anxiety. This study was limited by the relatively short follow-up (9 months after implantation). The authors rigorously reported adverse effects during the protocol, which notably included an air embolism during implantation and one instance of seizure during programming.

\section{Tourette Syndrome \\ Background}

Tourette syndrome is defined by the presence of motor and vocal tics-rapid, repetitive, stereotyped movements or vocalizations - that manifest before the age of 18 years and last for more than 12 months in the absence of secondary causes. ${ }^{157}$ Disease prevalence in children and adolescents has been estimated at $0.8 \%$, although this figure drops to $0.05 \%$ in adults. ${ }^{138}$ Symptoms typically present before puberty, with an average age at onset of 6.4 years, and a male predominance $(4.4: 1){ }^{20,237}$ The syndrome is often comorbid with other neuropsychiatric diseases such as OCD, attention deficit hyperactivity disorder, and other behavioral conditions. ${ }^{76}$ Most patients have improvements in their tics during late adolescence and early adulthood, but a subset of patients continues to experience disabling tics that are refractory to behavioral therapy and pharmacotherapy. ${ }^{203,206}$

Individuals with TS have demonstrated structural and functional abnormalities within the corticostriatothalamocortical loop, ${ }^{261,302}$ although the primary site of abnormality remains controversial. ${ }^{65}$ In fact, imaging studies in individuals with TS reveal widespread abnormalities in the size, connectivity, and microstructure of the caudate nucleus, ${ }^{158,222}$ thalamus, ${ }^{174}$ sensorimotor and prefrontal cortex, ${ }^{268}$ cerebellum, ${ }^{277}$ corpus callosum, ${ }^{41}$ amygdala and hippocampus, ${ }^{221}$ and limbic structures such as the amygdalae and NAcc. ${ }^{207}$ Electrophysiological studies implicate overexcitability and dysregulation of frontal-subcortical circuitry resulting in deficiencies in processing of stimuli. ${ }^{121,216,276,284}$ Histopathological and genomic studies provide evidence of structural alterations in the composition

TABLE 3. Selected studies of DBS for AN

\begin{tabular}{lclll}
\hline \multicolumn{1}{c}{ Authors \& Year } & No. of Pts & \multicolumn{1}{c}{ Study Type } & Target & \multicolumn{1}{c}{ Outcomes } \\
\hline McLaughlin et al., 2013 & 1 & Case report & VC/VS & Healthy weight \\
\hline Lipsman et al., 2013 & 6 & Prospective, open label & SCC & $50 \%$ w/ improvement in weight to near normal BMI \\
\hline Wang et al., 2013 & 2 & Case series & NAcc & Recovery of normal weight \& menstruation \\
\hline Wu et al., 2013 & 4 & Case series & NAcc & $\begin{array}{c}\text { Mean increase of } 65 \% \text { body weight; average postop BMl } \\
19.6\end{array}$ \\
\hline
\end{tabular}


of inhibitory $\gamma$-aminobutyric acidergic and cholinergic interneurons in the sensorimotor areas of the striatum and in the GP internus (GPi), suggesting an imbalance between inhibitor and excitatory regulation. ${ }^{125,162}$ Evidence for neurotransmitter dysfunction has been shown in dopaminergic, ${ }^{266}$ serotonergic, ${ }^{301}$ cholinergic, ${ }^{306}$ glutamatergic, ${ }^{5}$ and intracellular second messenger transmission. ${ }^{265}$

With so many physiological and anatomical sites implicated in the pathophysiology of this disease, it may be no surprise that more than 7 different targets for DBS have been investigated in trials for the treatment of TS, which are summarized in a recent review by Schrock et al ${ }^{254}$ The most common targets involve the centromedian-parafascicular thalamic complex (CM-PF) and the GPi. Selected studies are presented in Table 4, but see the aforementioned review for a comprehensive summary.

\section{Centromedian-Parafascicular Thalamic Complex}

The CM-PF is extensively connected to the basal ganglia, to sensory, motor, and premotor cortices, and to the anterior cingulate cortex, and it has been shown to be related to attentional processing. In particular, it is involved in the attentional shift to motivationally relevant stimuli. ${ }^{195}$ Studies targeting the CM-PF for DBS extensively cite early work done by Hassler and Dieckmann, who reported control over obsessional symptoms with thalamic ablation in $1970 .{ }^{235}$ Based on this early work, successful control of tics with DBS at the CM-PF was reported in $1999,{ }^{285}$ and more than 20 studies have subsequently reported successful treatment of TS with stimulation in the CM-PF and ventral tier of the thalamus. ${ }^{254}$ The majority of studies constitute Class IV evidence in the form of case reports ${ }^{2,4,21,159,263,289}$ or small case series, ${ }^{123,199,224,247,256}$ with many containing previously reported patients. ${ }^{149,183,225,257,290}$ Reported outcomes are variable, with 1 report of worsening tic behavior with stimulation, ${ }^{60}$ and some series reporting $100 \%$ reduction in tic frequency. ${ }^{146,285}$ Three studies meet Class III evidentiary criteria, with a total of 16 patients who showed $50 \%,{ }^{3}$ $44 \%,{ }^{172}$ and $19 \%{ }^{214}$ mean improvement in Yale Global Tic Severity Score (YGTSS).

In addition to the usual adverse events associated with DBS implantation, reported complications include visual disturbances, ${ }^{256}$ decreased energy levels and sexual function, ${ }^{3,290}$ reduced verbal fluency, ${ }^{146}$ an increased rate of wound healing and hardware complications, probably related to tic behavior, 2,225,257 and 1 report of psychogenic complications eventually leading to death by starvation. ${ }^{60}$

\section{Globus Pallidus}

Side effects of thalamic DBS for TS and evidence supporting the involvement of dopaminergic circuitry in the pathophysiology of tic development prompted exploration of stimulation at the GP for treatment of TS. A case report detailing the $47 \%$ reduction in YGTSS associated with stimulation at the GPi for TS was published in 2005.55 Multiple case reports ${ }^{50,56,59,79,258}$ and small case series ${ }^{49,185}$ followed, with the largest series reporting a mean decrease in YGTSS of 50\%..$^{39}$ The only Class III evidence supporting use of GPi in TS comes from 2 single-subject, blinded cross-over trials comparing stimulation at the CM-PF to that of the GPi in patients implanted at both sites. Both patients exhibited approximately $65 \%$ reduction in tic severity with stimulation at either site. ${ }^{10,294}$ Adverse events related to stimulation included bradykinesia, ${ }^{55}$ and reports of infective or hardware-related complications were similar to those seen in patients with thalamic stimulation. ${ }^{185,259}$

Other targets investigated for DBS to treat TS include the ALIC/NAcc ${ }^{68,152,208,307}$ and STN. ${ }^{185}$ Results range from a $20 \%$ worsening in tic severity ${ }^{38}$ to near abolition of tic behavior. ${ }^{186}$ Although outcomes have been favorable in most cases, most reports were uncontrolled and the outcomes measures varied between studies. Comorbidity with other neuropsychiatric disorders such as attention deficit hyperactivity disorder and OCD is common in patients with TS, further complicating treatment. To address some of this ongoing uncertainty, the Tourette Syndrome Association International Deep Brain Stimulation (DBS) Database and Registry Study Group issued updated recommendations for the treatment of TS with DBS in December 2014, highlighting the need for a multidisciplinary approach, emphasizing pre- and postoperative outcome measures, and proposing inclusion and exclusion criteria for DBS in patients with TS. ${ }^{254}$

\section{Addiction and Substance Use Disorder}

The term addiction is used loosely in modern society, generally to denote a pattern of persistent repetitive behaviors in the face of adverse consequences, whether medical, psychological, or societal. Commonly referenced addictions include substance abuse, gambling, and even Internet gaming, all of which are now listed as disorders in the 5th edition of the Diagnostic and Statistical Manual of Mental Disorders. The common element among these conditions is recurrent problematic behavior accompanied by a preoccupation with the behavior. Although substance abuse is often accompanied by a physical component, the persistent behaviors and preoccupations extend well after the physical withdrawal has faded, and craving and relapse rates are high even after detoxification. ${ }^{33}$ Given this pattern, it is acknowledged that the development of addiction is not simply based on the acute impact of the substance or behavior, ${ }^{66,142}$ but instead represents disequilibrium in the reward system. ${ }^{238}$

Animal models and neuroimaging studies in humans have identified broad alterations in prefrontal, limbic, and cortical areas that are involved in addiction and maladaptive behavior, ${ }^{72,84,117}$ but the most consistent core regions appear to be involved in the dopaminergic connection between the VTA and the NAcc, which modulates learning, memory, and repetitive behaviors. ${ }^{142}$ Animal studies on the NAcc have shown that stimulation consistently attenuates and modulates learned behaviors related to alcohol, cocaine, and other habit-forming substances, ${ }^{87,135,286}$ and DBS in the NAcc has been successful in treating other disorders of repetitive behaviors. ${ }^{30,303}$ Thus significant interest exists in stimulation of these areas for the treatment of the behavioral component in addiction and substance abuse disorder. Ablative surgeries targeted at the NAcc have been used for several years in China with mixed results, but a relapse rate of 50\% and ethical concerns now limit the use of destructive procedures in the treatment of addiction..$^{163,304,305}$ 


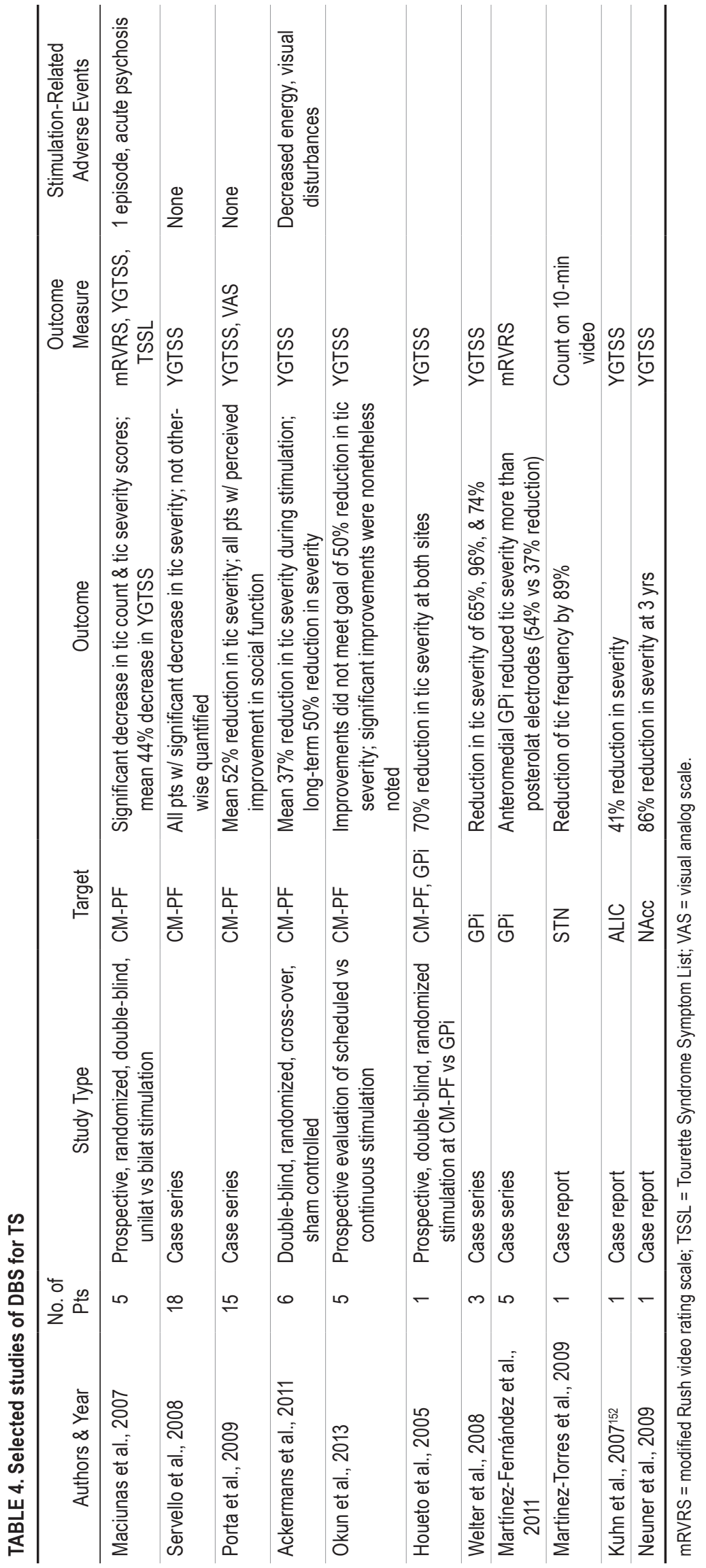


Although sparse, clinical data regarding the efficacy of NAcc stimulation exists in the literature in small case series. In 1 case study, a patient who was treated with bilateral NAcc stimulation for heroin addiction underwent explantation at 3 years postoperation, but remained abstinent from opioids to the last follow-up at 6 years. ${ }^{310} \mathrm{~A}$ similar case involved a man with a 22-year history of treatmentresistant heroin abuse who was implanted with bilateral DBS electrodes in the NAcc. During stimulation testing, different combinations of contacts and settings brought about both increased and decreased craving for substances, and with optimized stimulation parameters the patient was able to achieve abstinence for more than 6 months. ${ }^{280}$ Other limited trials have also been conducted with DBS for alcohol and nicotine addiction. Two separate cases of patients with chronic, severe alcoholism who were treated with DBS in the NAcc reported abstinence at 1 year. ${ }^{148,150}$ In another study of 5 patients with chronic alcoholism, 2 patients remained abstinent for more than 4 years, and the remainder had significant reduction in alcohol consumption. ${ }^{291}$ Several of the patients in the above series exhibited comorbid addiction to nicotine; these patients decreased their intake but none quit completely. ${ }^{310}$ In a single case of DBS at the NAcc for OCD, cessation of nicotine abuse was reported, ${ }^{181}$ but a subsequent analysis of 10 patients who received DBS of the NAcc for OCD, TS, or anxiety found that only 3 patients achieved nicotine abstinence by 30 months. ${ }^{147}$ These case reports and a couple of case series show the potential for treatment of substance abuse disorders with DBS of the NAcc, but randomized and blinded studies are lacking (Table 5).

\section{Aggressive Behavior}

Neurosurgery has been historically used for the management of aggressive behavior, although interest has waxed and waned. In the 1960s and 1970s, bilateral ablation of the amygdala was first used for treatment of epilepsy comorbid with aggression, but after early successes it became a common treatment for aggression. More than 1000 patients eventually received the procedure, with approximately $75 \%$ of these patients displaying no further aggressive behavior. ${ }^{171,201,204,205}$ Side effects of the procedure included reduced autonomic response to stressful cues, new-onset epilepsy, and hypersexual behavior, but overall these were limited to a small number of patients. Despite the high success rate of the surgery, subsequent public backlash against psychosurgery led to widely preferential use of pharmacological agents for behavioral control. More recently, though, increasing use of DBS has led to renewed interest in neurosurgical options for control of aggressive behavior, albeit in a reversible and adjustable fashion rather than a destructive one. A recent case report describes the use of bilateral DBS in the basolateral amygdalae for intractable self-injurious behavior associated with mental retardation and autism. ${ }^{270}$ The patient, a 13-year-old boy, had failed multiple trials of pharmacotherapy and behavioral therapy, but by 26 months postimplantation his self-injurious behavior had been reduced, although it was not eliminated. Another patient with selfinjurious behaviors, this time secondary to Lesch-Nyhan syndrome, experienced cessation of self-injury following DBS, although the stimulation was applied to the GPi for treatment of an unrelated movement disorder. ${ }^{273}$

Another site of interest in the treatment of aggressive behavior has been the posterior hypothalamic region $(\mathrm{pHr})$, a region that shows strong interconnection with the amygdalae. ${ }^{245}$ As in the amygdala, lesions in the $\mathrm{pHr}$ have been used for the combination of epilepsy and aggressive behavior. ${ }^{244,255}$ Modern application of DBS to the $\mathrm{pHr}$ has mostly been for cases of mental retardation combined with severe aggression, and thus few results have been reported. In the first of 2 cases in the literature, a 22 -year-old patient with mental retardation and aggression received bilateral low-frequency stimulation $(15 \mathrm{~Hz})$ to the $\mathrm{pHr}$, and at 18-month follow-up the patient's behavior was significantly improved. ${ }^{104} \mathrm{~A}$ second case involved a 22 -year-old patient with severe, involuntary self-injurious behavior after a traumatic brain injury. At 4 months after the initiation of stimulation, the patient was reported to have complete cessation of the behavior. ${ }^{151}$ The largest reported cohort for $\mathrm{pHr}$ stimulation was of 7 patients, ages 20-68 years, with IQs between 20 and 40 and uncontrollable aggressive and violent behavior. ${ }^{73-75}$ After implantation of DBS electrodes in the $\mathrm{pHr}, 6$ patients had cessation or significantly decreased outbursts of violent behavior. As is seen with other diseases, relapse of behavior occurred when the stimulation was interrupted or the battery became depleted (Table 6).

\section{Posttraumatic Stress Disorder}

Posttraumatic stress disorder is a psychiatric condition brought on by exposure to traumatic events, and produces cognitive, physical, and psychological disturbances accompanied by a broad range of symptoms, including hypervigilance, anxiety, aggressive behavior, sleep cycle disturbances, and intrusive thoughts. ${ }^{281}$ It affects $6.8 \%$ of the US population and is most common among military personnel. ${ }^{130,132}$ Current best treatments include pharmacotherapy and psychotherapy, but even with combination therapy as many as $30 \%$ of patients remain debilitated by the condition. ${ }^{36}$ Recent investigations into novel therapies for PTSD have identified changes in the CNS, specifically the amygdala, that occur in conjunction with the development of the condition. In patients with traumatic brain

TABLE 5. Selected studies of DBS for addiction

\begin{tabular}{cccccc}
\hline Authors \& Year & No. of Pts & Study Type & Target & Outcome & Outcome Measure \\
\hline Müller et al., 2009 & 3 & Case series & NAcc & 2 of 3 achieved abstinence at $1 \mathrm{yr}$ & Alcohol consumption \\
\hline Voges et al., 2013 & 5 & Case series & NAcc & 2 of 5 remained abstinent at 4 yrs; all reported & Alcohol consumption \\
& & & reduced craving & Heroin use \\
\hline Zhou et al., 2011 & 1 & Case report & NAcc & Abstinence for 6 yrs & \\
\hline
\end{tabular}


TABLE 6. Selected studies of DBS for aggressive or self-injurious behavior

\begin{tabular}{lccccc}
\hline \multicolumn{1}{c}{ Authors \& Year } & $\begin{array}{c}\text { No. of } \\
\text { Pts }\end{array}$ & Study Type & Target & Indication & Outcome Measure \\
\hline Sturm et al., 2012 & 1 & Case report & $\begin{array}{c}\text { Basolateral } \\
\text { amygdala }\end{array}$ & Kanner's autism & Less injurious behavior at 24 mos \\
\hline Franzini et al., 2005, 2007, 2013 & 7 & Case series & $\mathrm{pHr}$ & $\begin{array}{c}\text { Severe mental } \\
\text { retardation }\end{array}$ & $\begin{array}{c}\text { Reduced injurious behavior at } 1 \text { yr in } \\
6 \text { of } 7 \text { pts }\end{array}$ \\
\hline
\end{tabular}

injury, damage to the amygdala correlates with the development of PTSD. ${ }^{141}$ Direct stimulation to the amygdala can produce anger, and functional imaging studies have found increased activity of the amygdala in patients with PTSD. ${ }^{96,229}$ The increased activity of the amygdala is correlated with the degree of symptoms, and similarly, a decrease in amygdala activity corresponds to improvement and response to treatment. ${ }^{70}$

The amygdala is a bilateral structure of the mesiotemporal lobe with important connections to the hypothalamus and brainstem, and is best recognized for its role in emotional expression and fear conditioning. ${ }^{8,193,228}$ However, it has numerous subregions that have been tied to other limbic and associative functions. ${ }^{7,47}$ Animal models of PTSD have shown that stimulation of the amygdala relieves abnormal behaviors. ${ }^{155}$ Based on these cumulative results, the first trials of DBS in the amygdala were recently launched, although no results have been reported yet. ${ }^{140}$ The amygdala represents a promising target for patients suffering from treatment-refractory PTSD, and outcomes of early trials will shed further light into the utility of DBS as a novel treatment.

\section{Conclusions}

The history of psychosurgery in the mid-20th century provides valuable lessons for the continuing development of brain surgery for behavioral disorders. Psychiatric disease remains the major source of disability in the world. There have been developments, however, that may help those involved in surgery for psychiatric disease avoid the mistakes of the past.

Diagnostic criteria for these disorders has improved. An increased understanding of the physiology underlying these disorders provides a firmer foundation for interventions, and in some cases may provide a biomarker for successful treatment. Advances in the ability to image the brain and subcortical structures should facilitate accurate and safe placement of electrodes at effective stimulation sites. Engineering improvements may increase the effectiveness of DBS by shaping stimulation fields, reducing hardware complications, and eventually allowing patientresponsive stimulation.

However, unbridled enthusiasm would run the risk of repeating the widespread overusage of imperfect techniques that led to the initial backlash against psychiatric surgery. As in DBS for movement disorders, the neuromodulatory treatment of psychiatric illness should not be portrayed as a cure for these diseases. Management of patient expectations, as well as media portrayals of this treatment modality, must emphasize realistic outcomes rather than overly optimistic claims. Such premature optimism regarding the potential treatment of memory disorders and disorders of consciousness via surgical means is already evident. ${ }^{81}$ Ethical dilemmas inherent in popularization of potential treatments for refractory disease cannot be emphasized enough.

The ability to place electrodes safely within the brain is not a moral mandate to do so; the knowledge of which stimulation sites are most efficacious for a particular disease is likewise not an ethical warrant for insertion. Careful preoperative evaluation by multidisciplinary teams and the use of rigorous outcome measures are necessary to prevent the type of indiscriminate and irresponsible application of these techniques by isolated practitioners such as Walter Freeman.

The continuing challenge inherent in neurosurgery for psychiatric disorders will be to balance the urge to offer promising (but in truth still investigational) operations for treatment-resistant disease, with the need for careful evaluation of underlying physiology and outcomes data. This balance can perhaps be captured in the words of psychosurgery's first practitioner, Gottlieb Burckhardt, who observed that "Doctors are different by nature. One kind adheres to the old principle: first, do no harm (primum non nocere); the other one says: it is better to do something than do nothing (melius anceps remedium quam nullum)." ${ }^{180}$ The ideal and ethical doctor must do both.

\section{References}

1. Abelson JL, Curtis GC, Sagher O, Albucher RC, Harrigan $\mathrm{M}$, Taylor SF, et al: Deep brain stimulation for refractory obsessive-compulsive disorder. Biol Psychiatry 57:510516,2005

2. Ackermans L, Duits A, Temel Y, Winogrodzka A, Peeters F, Beuls EAM, et al: Long-term outcome of thalamic deep brain stimulation in two patients with Tourette syndrome. $\mathbf{J}$ Neurol Neurosurg Psychiatry 81:1068-1072, 2010

3. Ackermans L, Duits A, van der Linden C, Tijssen M, Schruers K, Temel Y, et al: Double-blind clinical trial of thalamic stimulation in patients with Tourette syndrome. Brain 134:832-844, 2011

4. Ackermans L, Temel Y, Cath D, van der Linden C, Bruggeman R, Kleijer M, et al: Deep brain stimulation in Tourette's syndrome: two targets? Mov Disord 21:709_ 713, 2006

5. Adamczyk A, Gause CD, Sattler R, Vidensky S, Rothstein JD, Singer H, et al: Genetic and functional studies of a missense variant in a glutamate transporter, SLC1A3, in Tourette syndrome. Psychiatr Genet 21:90-97, 2011

6. Adinoff B: Neurobiologic processes in drug reward and addiction. Harv Rev Psychiatry 12:305-320, 2004

7. Adolphs R, Tranel D, Damasio H, Damasio A: Impaired recognition of emotion in facial expressions following bilateral damage to the human amygdala. Nature 372:669-672, 1994 
8. Aggleton JP, Burton MJ, Passingham RE: Cortical and subcortical afferents to the amygdala of the rhesus monkey (Macaca mulatta). Brain Res 190:347-368, 1980

9. Aharon I, Etcoff N, Ariely D, Chabris CF, O'Connor E, Breiter HC: Beautiful faces have variable reward value: fMRI and behavioral evidence. Neuron 32:537-551, 2001

10. Al-Harbi KS: Treatment-resistant depression: therapeutic trends, challenges, and future directions. Patient Prefer Adherence 6:369-388, 2012

11. Alegret M, Junqué C, Valldeoriola F, Vendrell P, Martí MJ, Tolosa E: Obsessive-compulsive symptoms in Parkinson's disease. J Neurol Neurosurg Psychiatry 70:394-396, 2001

12. Alt KW, Jeunesse C, Buitrago-Téllez CH, Wächter R, Boës E, Pichler SL: Evidence for stone age cranial surgery. Nature 387:360, 1997 (Letter)

13. Altman SE, Shankman SA: What is the association between obsessive-compulsive disorder and eating disorders? Clin Psychol Rev 29:638-646, 2009

14. Anderson D, Ahmed A: Treatment of patients with intractable obsessive-compulsive disorder with anterior capsular stimulation. Case report. J Neurosurg 98:1104-1108, 2003

15. Andrade L, Caraveo-Anduaga JJ, Berglund P, Bijl RV, De Graaf R, Vollebergh W, et al: The epidemiology of major depressive episodes: results from the International Consortium of Psychiatric Epidemiology (ICPE) Surveys. Int J Methods Psychiatr Res 12:3-21, 2003

16. Aouizerate B, Cuny E, Bardinet E, Yelnik J, Martin-Guehl C, Rotge JY, et al: Distinct striatal targets in treating obsessive-compulsive disorder and major depression. J Neurosurg 111:775-779, 2009

17. Aouizerate B, Cuny E, Martin-Guehl C, Guehl D, Amieva $\mathrm{H}$, Benazzouz A, et al: Deep brain stimulation of the ventral caudate nucleus in the treatment of obsessive-compulsive disorder and major depression. Case report. J Neurosurg 101:682-686, 2004

18. Ardouin C, Voon V, Worbe Y, Abouazar N, Czernecki V, Hosseini H, et al: Pathological gambling in Parkinson's disease improves on chronic subthalamic nucleus stimulation. Mov Disord 21:1941-1946, 2006

19. Aron AR, Poldrack RA: Cortical and subcortical contributions to Stop signal response inhibition: role of the subthalamic nucleus. J Neurosci 26:2424-2433, 2006

20. Bagheri MM, Kerbeshian J, Burd L: Recognition and management of Tourette's syndrome and tic disorders. Am Fam Physician 59:2263-2272, 2274, 1999

21. Bajwa RJ, de Lotbinière AJ, King RA, Jabbari B, Quatrano $\mathrm{S}$, Kunze K, et al: Deep brain stimulation in Tourette's syndrome. Mov Disord 22:1346-1350, 2007

22. Ballantine HT Jr, Bouckoms AJ, Thomas EK, Giriunas IE: Treatment of psychiatric illness by stereotactic cingulotomy. Biol Psychiatry 22:807-819, 1987

23. Barbier J, Gabriëls L, van Laere K, Nuttin B: Successful anterior capsulotomy in comorbid anorexia nervosa and obsessive-compulsive disorder: case report. Neurosurgery 69:E745-751, 2011

24. Bebbington PE: Epidemiology of obsessive-compulsive disorder. Br J Psychiatry 173 (Suppl 35):2-6, 1998

25. Benabid AL, Pollak P, Gao D, Hoffmann D, Limousin P, Gay E, et al: Chronic electrical stimulation of the ventralis intermedius nucleus of the thalamus as a treatment of movement disorders. J Neurosurg 84:203-214, 1996

26. Berridge KC: Pleasures of the brain. Brain Cogn 52:106128,2003

27. Bewernick BH, Hurlemann R, Matusch A, Kayser S, Grubert C, Hadrysiewicz B, et al: Nucleus accumbens deep brain stimulation decreases ratings of depression and anxiety in treatment-resistant depression. Biol Psychiatry 67:110-116, 2010

28. Bewernick BH, Kayser S, Sturm V, Schlaepfer TE: Long- term effects of nucleus accumbens deep brain stimulation in treatment-resistant depression: evidence for sustained efficacy. Neuropsychopharmacology 37:1975-1985, 2012

29. Björgvinsson T, Hart J, Heffelfinger S: Obsessivecompulsive disorder: update on assessment and treatment. J Psychiatr Pract 13:362-372, 2007

30. Blomstedt P, Sjöberg RL, Hansson M, Bodlund O, Hariz MI: Deep brain stimulation in the treatment of obsessivecompulsive disorder. World Neurosurg 80:e245-e253, 2013

31. Blood AJ, Zatorre RJ: Intensely pleasurable responses to music correlate with activity in brain regions implicated in reward and emotion. Proc Natl Acad Sci U S A 98:1181811823, 2001

32. Boschen MJ, Drummond LM, Pillay A, Morton K: Predicting outcome of treatment for severe, treatment resistant OCD in inpatient and community settings. J Behav Ther Exp Psychiatry 41:90-95, 2010

33. Bradizza CM, Stasiewicz PR, Paas ND: Relapse to alcohol and drug use among individuals diagnosed with co-occurring mental health and substance use disorders: a review. Clin Psychol Rev 26:162-178, 2006

34. Breiter HC, Gollub RL, Weisskoff RM, Kennedy DN, Makris N, Berke JD, et al: Acute effects of cocaine on human brain activity and emotion. Neuron 19:591-611, 1997

35. Breiter HC, Rauch SL, Kwong KK, Baker JR, Weisskoff RM, Kennedy DN, et al: Functional magnetic resonance imaging of symptom provocation in obsessive-compulsive disorder. Arch Gen Psychiatry 53:595-606, 1996

36. Breslau N: Outcomes of posttraumatic stress disorder. J Clin Psychiatry 62 (Suppl 17):55-59, 2001

37. Broca P: Du siège de la faculté du langage articulé. Bull Soc Anthropol Paris 6:337-393, 1865

38. Burdick A, Foote KD, Goodman W, Ward HE, Ricciuti N, Murphy T, et al: Lack of benefit of accumbens/capsular deep brain stimulation in a patient with both tics and obsessive-compulsive disorder. Neurocase 16:321-330, 2010

39. Cannon E, Silburn P, Coyne T, O’Maley K, Crawford JD, Sachdev PS: Deep brain stimulation of anteromedial globus pallidus interna for severe Tourette's syndrome. Am J Psychiatry 169:860-866, 2012

40. Cardinal RN, Parkinson JA, Hall J, Everitt BJ: Emotion and motivation: the role of the amygdala, ventral striatum, and prefrontal cortex. Neurosci Biobehav Rev 26:321-352, 2002

41. Cavanna AE, Stecco A, Rickards H, Servo S, Terazzi E, Peterson B, et al: Corpus callosum abnormalities in Tourette syndrome: an MRI-DTI study of monozygotic twins. J Neurol Neurosurg Psychiatry 81:533-535, 2010

42. Cersosimo MG, Raina GB, Benarroch EE, Piedimonte F, Alemán GG, Micheli FE: Micro lesion effect of the globus pallidus internus and outcome with deep brain stimulation in patients with Parkinson disease and dystonia. Mov Disord 24:1488-1493, 2009

43. Cheng Y, Xu J, Nie B, Luo C, Yang T, Li H, et al: Abnormal resting-state activities and functional connectivities of the anterior and the posterior cortexes in medicationnaïve patients with obsessive-compulsive disorder. PLoS One 8:e67478, 2013

44. Coenen VA, Schlaepfer TE, Allert N, Mädler B: Diffusion tensor imaging and neuromodulation: DTI as key technology for deep brain stimulation. Int Rev Neurobiol 107:207234, 2012

45. Coenen VA, Schlaepfer TE, Maedler B, Panksepp J: Crossspecies affective functions of the medial forebrain bundleimplications for the treatment of affective pain and depression in humans. Neurosci Biobehav Rev 35:1971-1981, 2011 
46. Cui C, Noronha A, Morikawa H, Alvarez VA, Stuber GD, Szumlinski KK, et al: New insights on neurobiological mechanisms underlying alcohol addiction. Neuropharmacology 67:223-232, 2013

47. Davis M: The role of the amygdala in fear and anxiety. Annu Rev Neurosci 15:353-375, 1992

48. de la Fuente-Fernández R, Phillips AG, Zamburlini M, Sossi V, Calne DB, Ruth TJ, et al: Dopamine release in human ventral striatum and expectation of reward. Behav Brain Res 136:359-363, 2002

49. Dehning S, Feddersen B, Cerovecki A, Bötzel K, Müller N, Mehrkens JH: Globus pallidus internus-deep brain stimulation in Tourette's syndrome: can clinical symptoms predict response? Mov Disord 26:2440-2441, 2011

50. Dehning S, Mehrkens JH, Müller N, Bötzel K: Therapyrefractory Tourette syndrome: beneficial outcome with globus pallidus internus deep brain stimulation. Mov Disord 23:1300-1302, 2008

51. Delgado JM, Hamlin H, Chapman WP: Technique of intracranial electrode implacement for recording and stimulation and its possible therapeutic value in psychotic patients. Confin Neurol 12:315-319, 1952

52. Denys D: Pharmacotherapy of obsessive-compulsive disorder and obsessive-compulsive spectrum disorders. Psychiatr Clin North Am 29:553-584, xi, 2006

53. Denys D, Mantione M, Figee M, van den Munckhof $P$, Koerselman F, Westenberg H, et al: Deep brain stimulation of the nucleus accumbens for treatment-refractory obsessive-compulsive disorder. Arch Gen Psychiatry 67:10611068,2010

54. Deuschl G, Schade-Brittinger C, Krack P, Volkmann J, Schäfer H, Bötzel K, et al: A randomized trial of deep-brain stimulation for Parkinson's disease. N Engl J Med 355: 896-908, 2006

55. Diederich NJ, Kalteis K, Stamenkovic M, Pieri V, Alesch F: Efficient internal pallidal stimulation in Gilles de la Tourette syndrome: a case report. Mov Disord 20:1496-1499, 2005

56. Dong S, Hu YS, Du W, Tao W, Zhang XH, Zhuang P, et al: Changes in spontaneous dorsal horn potentials after dorsal root entry zone lesioning in patients with pain after brachial plexus avulsion. J Int Med Res 40:1499-1506, 2012

57. Dougherty DD, Rezai AR, Carpenter LL, Howland RH, Bhati MT, O'Reardon JP, et al: A randomized sham-controlled trial of deep brain stimulation of the ventral capsule/ ventral striatum for chronic treatment-resistant depression. Biol Psychiatry [epub ahead of print], 2014

58. Drevets WC, Gautier C, Price JC, Kupfer DJ, Kinahan PE, Grace AA, et al: Amphetamine-induced dopamine release in human ventral striatum correlates with euphoria. Biol Psychiatry 49:81-96, 2001

59. Dueck A, Wolters A, Wunsch K, Bohne-Suraj S, Mueller JU, Haessler F, et al: Deep brain stimulation of globus pallidus internus in a 16-year-old boy with severe Tourette syndrome and mental retardation. Neuropediatrics 40:239 242, 2009

60. Duits A, Ackermans L, Cath D, Visser-Vandewalle V: Unfavourable outcome of deep brain stimulation in a Tourette patient with severe comorbidity. Eur Child Adolesc Psychiatry 21:529-531, 2012

61. Eagle DM, Baunez C, Hutcheson DM, Lehmann O, Shah AP, Robbins TW: Stop-signal reaction-time task performance: role of prefrontal cortex and subthalamic nucleus. Cereb Cortex 18:178-188, 2008

62. Epstein J, Pan H, Kocsis JH, Yang Y, Butler T, Chusid J, et al: Lack of ventral striatal response to positive stimuli in depressed versus normal subjects. Am J Psychiatry 163: 1784-1790, 2006

63. Faria MA: Violence, mental illness, and the brain - a brief history of psychosurgery: Part 1-From trephination to lobotomy. Surg Neurol Int 4:49, 2013
64. Fava M: Diagnosis and definition of treatment-resistant depression. Biol Psychiatry 53:649-659, 2003

65. Felling RJ, Singer HS: Neurobiology of Tourette syndrome: current status and need for further investigation. J Neurosci 31:12387-12395, 2011

66. Feltenstein MW, See RE: The neurocircuitry of addiction: an overview. Br J Pharmacol 154:261-274, 2008

67. Fins JJ, Mayberg HS, Nuttin B, Kubu CS, Galert T, Sturm $\mathrm{V}$, et al: Misuse of the FDA's humanitarian device exemption in deep brain stimulation for obsessive-compulsive disorder. Health Aff (Millwood) 30:302-311, 2011

68. Flaherty AW, Williams ZM, Amirnovin R, Kasper E, Rauch SL, Cosgrove GR, et al: Deep brain stimulation of the anterior internal capsule for the treatment of Tourette syndrome: technical case report. Neurosurgery 57 (4 Suppl):E403, 2005

69. Fontaine D, Mattei V, Borg M, von Langsdorff D, Magnie $\mathrm{MN}$, Chanalet S, et al: Effect of subthalamic nucleus stimulation on obsessive-compulsive disorder in a patient with Parkinson disease. Case report. J Neurosurg 100:10841086, 2004

70. Francati V, Vermetten E, Bremner JD: Functional neuroimaging studies in posttraumatic stress disorder: review of current methods and findings. Depress Anxiety 24:202-218, 2007

71. Frank S, Wilms B, Veit R, Ernst B, Thurnheer M, Kullmann $\mathrm{S}$, et al: Altered brain activity in severely obese women may recover after Roux-en Y gastric bypass surgery. Int J Obes 38:341-348, 2013

72. Franklin TR, Acton PD, Maldjian JA, Gray JD, Croft JR, Dackis CA, et al: Decreased gray matter concentration in the insular, orbitofrontal, cingulate, and temporal cortices of cocaine patients. Biol Psychiatry 51:134-142, 2002

73. Franzini A, Broggi G, Cordella R, Dones I, Messina G: Deep-brain stimulation for aggressive and disruptive behavior. World Neurosurg 80:S29.e11-S29.e14, 2013

74. Franzini A, Marras C, Ferroli P, Bugiani O, Broggi G: Stimulation of the posterior hypothalamus for medically intractable impulsive and violent behavior. Stereotact Funct Neurosurg 83:63-66, 2005

75. Franzini A, Marras C, Tringali G, Leone M, Ferroli P, Bussone $\mathrm{G}$, et al: Chronic high frequency stimulation of the posteromedial hypothalamus in facial pain syndromes and behaviour disorders. Acta Neurochir Suppl 97:399-406, 2007

76. Freeman RD, Fast DK, Burd L, Kerbeshian J, Robertson MM, Sandor P: An international perspective on Tourette syndrome: selected findings from 3,500 individuals in 22 countries. Dev Med Child Neurol 42:436-447, 2000

77. Fulton J, Jacobsen C: The functions of the frontal lobes: A comparative study in monkeys, chimpanzees, and man. Adv Mod Biol (Moscow) 4:113-123, 1935

78. Gabriëls L, Cosyns P, Nuttin B, Demeulemeester H, Gybels $\mathrm{J}$ : Deep brain stimulation for treatment-refractory obsessivecompulsive disorder: psychopathological and neuropsychological outcome in three cases. Acta Psychiatr Scand 107:275-282, 2003

79. Gallagher CL, Garell PC, Montgomery EB Jr: Hemi tics and deep brain stimulation. Neurology 66:E12, 2006

80. Garner DM, Olmsted MP, Bohr Y, Garfinkel PE: The eating attitudes test: psychometric features and clinical correlates. Psychol Med 12:871-878, 1982

81. Gilbert F, Ovadia D: Deep brain stimulation in the media: over-optimistic portrayals call for a new strategy involving journalists and scientists in ethical debates. Front Integr Neurosci 5:16, 2011

82. Göktepe EO, Young LB, Bridges PK: A further review of the results of sterotactic subcaudate tractotomy. $\mathbf{B r} \mathbf{J}$ Psychiatry 126:270-280, 1975 
83. Goldapple K, Segal Z, Garson C, Lau M, Bieling P, Kennedy S, et al: Modulation of cortical-limbic pathways in major depression: treatment-specific effects of cognitive behavior therapy. Arch Gen Psychiatry 61:34-41, 2004

84. Goldstein RZ, Volkow ND: Drug addiction and its underlying neurobiological basis: neuroimaging evidence for the involvement of the frontal cortex. Am J Psychiatry 159:1642-1652, 2002

85. Goodman WK, Foote KD, Greenberg BD, Ricciuti N, Bauer $\mathrm{R}$, Ward H, et al: Deep brain stimulation for intractable obsessive compulsive disorder: pilot study using a blinded, staggered-onset design. Biol Psychiatry 67:535-542, 2010

86. Goodman WK, Price LH, Rasmussen SA, Mazure C, Fleischmann RL, Hill CL, et al: The Yale-Brown Obsessive Compulsive Scale. I. Development, use, and reliability. Arch Gen Psychiatry 46:1006-1011, 1989

87. Goto Y, Grace AA: Limbic and cortical information processing in the nucleus accumbens. Trends Neurosci 31:552-558, 2008

88. Greenberg BD, Gabriels LA, Malone DA Jr, Rezai AR, Friehs GM, Okun MS, et al: Deep brain stimulation of the ventral internal capsule/ventral striatum for obsessive-compulsive disorder: worldwide experience. Mol Psychiatry 15:64-79, 2010

89. Greenberg BD, Malone DA, Friehs GM, Rezai AR, Kubu CS, Malloy PF, et al: Three-year outcomes in deep brain stimulation for highly resistant obsessive-compulsive disorder. Neuropsychopharmacology 31:2384-2393, 2006

90. Greenberg BD, Price LH, Rauch SL, Friehs G, Noren G, Malone D, et al: Neurosurgery for intractable obsessivecompulsive disorder and depression: critical issues. Neurosurg Clin N Am 14:199-212, 2003

91. Gross D, Schäfer G: Egas Moniz (1874-1955) and the "invention" of modern psychosurgery: a historical and ethical reanalysis under special consideration of Portuguese original sources. Neurosurg Focus 30(2):E8, 2011

92. Grubert C, Hurlemann R, Bewernick BH, Kayser S, Hadrysiewicz B, Axmacher N, et al: Neuropsychological safety of nucleus accumbens deep brain stimulation for major depression: effects of 12-month stimulation. World J Biol Psychiatry 12:516-527, 2011

93. Guehl D, Benazzouz A, Aouizerate B, Cuny E, Rotgé JY, Rougier A, et al: Neuronal correlates of obsessions in the caudate nucleus. Biol Psychiatry 63:557-562, 2008

94. Guinjoan SM, Mayberg HS, Costanzo EY, Fahrer RD, Tenca E, Antico J, et al: Asymmetrical contribution of brain structures to treatment-resistant depression as illustrated by effects of right subgenual cingulum stimulation. $\mathbf{J}$ Neuropsychiatry Clin Neurosci 22:265-277, 2010

95. Haber SN: The primate basal ganglia: parallel and integrative networks. J Chem Neuroanat 26:317-330, 2003

96. Halgren E, Walter RD, Cherlow DG, Crandall PH: Mental phenomena evoked by electrical stimulation of the human hippocampal formation and amygdala. Brain 101:83-117, 1978

97. Hamani C, Mayberg H, Snyder B, Giacobbe P, Kennedy S, Lozano AM: Deep brain stimulation of the subcallosal cingulate gyrus for depression: anatomical location of active contacts in clinical responders and a suggested guideline for targeting. J Neurosurg 111:1209-1215, 2009

98. Hamani C, Pilitsis J, Rughani AI, Rosenow JM, Patil PG, Slavin KS, et al: Deep brain stimulation for obsessivecompulsive disorder: systematic review and evidencebased guideline sponsored by the American Society for Stereotactic and Functional Neurosurgery and the Congress of Neurological Surgeons (CNS) and endorsed by the CNS and American Association of Neurological Surgeons. Neurosurgery 75:327-333, 2014

99. Haq IU, Foote KD, Goodman WG, Wu SS, Sudhyadhom
A, Ricciuti N, et al: Smile and laughter induction and intraoperative predictors of response to deep brain stimulation for obsessive-compulsive disorder. Neuroimage 54 (Suppl 1):S247-S255, 2011

100. Hariz MI: Neurosurgeons were indeed promoting evidencebased, ethical, and multidisciplinary psychiatric surgery! Stereotact Funct Neurosurg 91:270-271, 2013 (Letter)

101. Hariz MI, Blomstedt P, Zrinzo L: Deep brain stimulation between 1947 and 1987: the untold story. Neurosurg Focus 29(2):E1, 2010

102. Harlow JM: Recovery from the passage of an iron bar through the head. Publ Mass Med Soc 2:327-347, 1868

103. Heimer L: Basal forebrain in the context of schizophrenia. Brain Res Brain Res Rev 31:205-235, 2000

104. Hernando V, Pastor J, Pedrosa M, Peña E, Sola RG: Lowfrequency bilateral hypothalamic stimulation for treatment of drug-resistant aggressiveness in a young man with mental retardation. Stereotact Funct Neurosurg 86:219-223, 2008

105. Hoek HW, van Hoeken D: Review of the prevalence and incidence of eating disorders. Int J Eat Disord 34:383-396, 2003

106. Hoffman JL: Clinical observations concerning schizophrenic patients treated by prefrontal leukotomy. N Engl J Med 241:233-236, 1949

107. Hollander E: Obsessive-compulsive disorder: the hidden epidemic. J Clin Psychiatry 58 (Suppl 12):3-6, 1997

108. Holtzheimer PE, Kelley ME, Gross RE, Filkowski MM, Garlow SJ, Barrocas A, et al: Subcallosal cingulate deep brain stimulation for treatment-resistant unipolar and bipolar depression. Arch Gen Psychiatry 69:150-158, 2012

109. Hou J, Wu W, Lin Y, Wang J, Zhou D, Guo J, et al: Localization of cerebral functional deficits in patients with obsessive-compulsive disorder: a resting-state fMRI study. J Affect Disord 138:313-321, 2012

110. Houeto JL, Karachi C, Mallet L, Pillon B, Yelnik J, Mesnage V, et al: Tourette's syndrome and deep brain stimulation. J Neurol Neurosurg Psychiatry 76:992-995, 2005

111. Huff W, Lenartz D, Schormann M, Lee SH, Kuhn J, Koulousakis A, et al: Unilateral deep brain stimulation of the nucleus accumbens in patients with treatment-resistant obsessive-compulsive disorder: outcomes after one year. Clin Neurol Neurosurg 112: 137-143, 2010

112. Hughes KC, Shin LM: Functional neuroimaging studies of post-traumatic stress disorder. Expert Rev Neurother 11: 275-285, 2011

113. Islam L, Franzini A, Messina G, Scarone S, Gambini O: Deep brain stimulation of the nucleus accumbens and bed nucleus of stria terminalis for obsessive-compulsive disorder: a case series. World Neurosurg [epub ahead of print], 2014

114. Israël M, Steiger H, Kolivakis T, McGregor L, Sadikot AF: Deep brain stimulation in the subgenual cingulate cortex for an intractable eating disorder. Biol Psychiatry 67:e53-e54, 2010

115. Jeanmonod D, Schulman J, Ramirez R, Cancro R, Lanz M, Morel A, et al: Neuropsychiatric thalamocortical dysrhythmia: surgical implications. Neurosurg Clin N Am 14:251265, 2003

116. Jenike MA: Neurosurgical treatment of obsessive-compulsive disorder. Br J Psychiatry 173 (Suppl 35):79-90, 1998

117. Jentsch JD, Taylor JR: Impulsivity resulting from frontostriatal dysfunction in drug abuse: implications for the control of behavior by reward-related stimuli. Psychopharmacology (Berl) 146:373-390, 1999

118. Jiménez F, Nicolini H, Lozano AM, Piedimonte F, Salin $\mathrm{R}$, Velasco F: Electrical stimulation of the inferior thalamic peduncle in the treatment of major depression and obsessive compulsive disorders. World Neurosurg 80:S30.e17-S30. e25, 2013 
119. Jiménez F, Velasco F, Salin-Pascual R, Hernández JA, Velasco M, Criales JL, et al: A patient with a resistant major depression disorder treated with deep brain stimulation in the inferior thalamic peduncle. Neurosurgery 57:585-593, 2005

120. Jiménez-Ponce F, Velasco-Campos F, Castro-Farfán G, Nicolini H, Velasco AL, Salín-Pascual R, et al: Preliminary study in patients with obsessive-compulsive disorder treated with electrical stimulation in the inferior thalamic peduncle. Neurosurgery 65 (6 Suppl):203-209, 2009

121. Johannes S, Wieringa BM, Nager W, Müller-Vahl KR, Dengler R, Münte TF: Electrophysiological measures and dual-task performance in Tourette syndrome indicate deficient divided attention mechanisms. Eur J Neurol 8:253260, 2001

122. Juckel G, Schlagenhauf F, Koslowski M, Wüstenberg T, Villringer A, Knutson B, et al: Dysfunction of ventral striatal reward prediction in schizophrenia. Neuroimage 29:409-416, 2006

123. Kaido T, Otsuki T, Kaneko Y, Takahashi A, Omori M, Okamoto T: Deep brain stimulation for Tourette syndrome: a prospective pilot study in Japan. Neuromodulation 14:123-129, 2011

124. Karachi C, Yelnik J, Tandé D, Tremblay L, Hirsch EC, François C: The pallidosubthalamic projection: an anatomical substrate for nonmotor functions of the subthalamic nucleus in primates. Mov Disord 20:172-180, 2005

125. Kataoka Y, Kalanithi PSA, Grantz H, Schwartz ML, Saper C, Leckman JF, et al: Decreased number of parvalbumin and cholinergic interneurons in the striatum of individuals with Tourette syndrome. J Comp Neurol 518:277-291, 2010

126. Keller MB, Lavori PW, Mueller TI, Endicott J, Coryell W, Hirschfeld RM, et al: Time to recovery, chronicity, and levels of psychopathology in major depression. A 5-year prospective follow-up of 431 subjects. Arch Gen Psychiatry 49:809-816, 1992

127. Kelly D, Richardson A, Mitchell-Heggs N: Stereotactic limbic leucotomy: neurophysiological aspects and operative technique. Br J Psychiatry 123:133-140, 1973

128. Kennedy SH, Evans KR, Krüger S, Mayberg HS, Meyer JH, McCann S, et al: Changes in regional brain glucose metabolism measured with positron emission tomography after paroxetine treatment of major depression. Am J Psychiatry 158:899-905, 2001

129. Kennedy SH, Giacobbe P, Rizvi SJ, Placenza FM, Nishikawa Y, Mayberg HS, et al: Deep brain stimulation for treatment-resistant depression: follow-up after 3 to 6 years. Am J Psychiatry 168:502-510, 2011

130. Kessler RC: Posttraumatic stress disorder: the burden to the individual and to society. J Clin Psychiatry 61 (Suppl 5):4-14, 2000

131. Kessler RC, Chiu WT, Demler O, Merikangas KR, Walters EE: Prevalence, severity, and comorbidity of 12-month DSM-IV disorders in the National Comorbidity Survey Replication. Arch Gen Psychiatry 62:617-627, 2005

132. Kessler RC, Sonnega A, Bromet E, Hughes M, Nelson CB: Posttraumatic stress disorder in the National Comorbidity Survey. Arch Gen Psychiatry 52:1048-1060, 1995

133. Kiening K, Sartorius A: A new translational target for deep brain stimulation to treat depression. EMBO Mol Med 5:1151-1153, 2013

134. Kim MC, Lee TK, Choi CR: Review of long-term results of stereotactic psychosurgery. Neurol Med Chir (Tokyo) 42:365-371, 2002

135. Knapp CM, Tozier L, Pak A, Ciraulo DA, Kornetsky C: Deep brain stimulation of the nucleus accumbens reduces ethanol consumption in rats. Pharmacol Biochem Behav 92:474-479, 2009
136. Knight G: Stereotactic tractotomy in the surgical treatment of mental illness. J Neurol Neurosurg Psychiatry 28:304310,1965

137. Knight GC, Tredgold RF: Orbital leucotomy; a review of 52 cases. Lancet 268:981-986, 1955

138. Knight T, Steeves T, Day L, Lowerison M, Jette N, Pringsheim T: Prevalence of tic disorders: a systematic review and meta-analysis. Pediatr Neurol 47:77-90, 2012

139. Knutson B, Adams CM, Fong GW, Hommer D: Anticipation of increasing monetary reward selectively recruits nucleus accumbens. J Neurosci 21:RC159, 2001

140. Koek RJ, Langevin JP, Krahl SE, Kosoyan HJ, Schwartz HN, Chen JW, et al: Deep brain stimulation of the basolateral amygdala for treatment-refractory combat posttraumatic stress disorder (PTSD): study protocol for a pilot randomized controlled trial with blinded, staggered onset of stimulation. Trials 15:356, 2014

141. Koenigs M, Huey ED, Raymont V, Cheon B, Solomon J, Wassermann EM, et al: Focal brain damage protects against post-traumatic stress disorder in combat veterans. Nat Neurosci 11:232-237, 2008

142. Koob GF, Volkow ND: Neurocircuitry of addiction. Neuropsychopharmacology 35:217-238, 2010

143. Krack P, Batir A, Van Blercom N, Chabardes S, Fraix V, Ardouin C, et al: Five-year follow-up of bilateral stimulation of the subthalamic nucleus in advanced Parkinson's disease. N Engl J Med 349:1925-1934, 2003

144. Krack P, Kumar R, Ardouin C, Dowsey PL, McVicker JM, Benabid AL, et al: Mirthful laughter induced by subthalamic nucleus stimulation. Mov Disord 16:867-875, 2001

145. Krischel M, Moll F, Van Kerrebroeck P: A stone never cut for: a new interpretation of The Cure of Folly by Jheronimus Bosch. Urol Int 93:389-393, 2014

146. Kuhn J, Bartsch C, Lenartz D, Huys D, Daumann J, Woopen C, et al: Clinical effectiveness of unilateral deep brain stimulation in Tourette syndrome. Transl Psychiatry 1:e52, 2011

147. Kuhn J, Bauer R, Pohl S, Lenartz D, Huff W, Kim EH, et al: Observations on unaided smoking cessation after deep brain stimulation of the nucleus accumbens. Eur Addict Res 15:196-201, 2009

148. Kuhn J, Gründler TO, Bauer R, Huff W, Fischer AG, Lenartz D, et al: Successful deep brain stimulation of the nucleus accumbens in severe alcohol dependence is associated with changed performance monitoring. Addict Biol 16:620-623, 2011

149. Kuhn J, Janouschek H, Raptis M, Rex S, Lenartz D, Neuner I, et al: In vivo evidence of deep brain stimulation-induced dopaminergic modulation in Tourette's syndrome. Biol Psychiatry 71:e11-e13, 2012

150. Kuhn J, Lenartz D, Huff W, Lee S, Koulousakis A, Klosterkoetter J, et al: Remission of alcohol dependency following deep brain stimulation of the nucleus accumbens: valuable therapeutic implications? J Neurol Neurosurg Psychiatry 78:1152-1153, 2007

151. Kuhn J, Lenartz D, Mai JK, Huff W, Klosterkoetter J, Sturm V: Disappearance of self-aggressive behavior in a brain-injured patient after deep brain stimulation of the hypothalamus: technical case report. Neurosurgery 62:E1182, 2008

152. Kuhn J, Lenartz D, Mai JK, Huff W, Lee SH, Koulousakis A, et al: Deep brain stimulation of the nucleus accumbens and the internal capsule in therapeutically refractory Tourette-syndrome. J Neurol 254:963-965, 2007

153. Kullmann S, Heni M, Linder K, Zipfel S, Häring HU, Veit $\mathrm{R}$, et al: Resting-state functional connectivity of the human hypothalamus. Hum Brain Mapp 35:6088-6096, 2014

154. Kupfer DJ, Frank E, Phillips ML: Major depressive disorder: new clinical, neurobiological, and treatment perspectives. Lancet 379: 1045-1055, 2012 
155. Langevin JP, De Salles AA, Kosoyan HP, Krahl SE: Deep brain stimulation of the amygdala alleviates post-traumatic stress disorder symptoms in a rat model. J Psychiatr Res 44:1241-1245, 2010

156. Lapidus KAB, Kopell BH, Ben-Haim S, Rezai AR, Goodman WK: History of psychosurgery: a psychiatrist's perspective. World Neurosurg 80:S27.e1-S27.e16, 2013

157. Leckman JF, Bloch MH, Scahill L, King RA: Tourette syndrome: the self under siege. J Child Neurol 21:642-649, 2006

158. Leckman JF, Bloch MH, Smith ME, Larabi D, Hampson M: Neurobiological substrates of Tourette's disorder. J Child Adolesc Psychopharmacol 20:237-247, 2010

159. Lee MW, Au-Yeung MM, Hung KN, Wong CK: Deep brain stimulation in a Chinese Tourette's syndrome patient. Hong Kong Med J 17:147-150, 2011

160. Leiphart JW, Valone FH III: Stereotactic lesions for the treatment of psychiatric disorders. J Neurosurg 113:12041211,2010

161. Leksell L: A stereotaxic apparatus for intracerebral surgery. Acta Chir Scand 99:229-233, 1949

162. Lennington JB, Coppola G, Kataoka-Sasaki Y, Fernandez TV, Palejev D, Li Y, et al: Transcriptome analysis of the human striatum in Tourette syndrome. Biol Psychiatry [epub ahead of print], 2014

163. Li N, Wang J, Wang XL, Chang CW, Ge SN, Gao L, et al: Nucleus accumbens surgery for addiction. World Neurosurg 80:S28.e9-S28.e19, 2013

164. Lippitz BE, Mindus P, Meyerson BA, Kihlström L, Lindquist $\mathrm{C}$ : Lesion topography and outcome after thermocapsulotomy or gamma knife capsulotomy for obsessivecompulsive disorder: relevance of the right hemisphere. Neurosurgery 44:452-460, 1999

165. Lipsman N, Meyerson BA, Lozano AM: A narrative history of the international society for psychiatric surgery: 1970 1983. Stereotact Funct Neurosurg 90:347-355, 2012

166. Lipsman N, Woodside DB, Giacobbe P, Hamani C, Carter JC, Norwood SJ, et al: Subcallosal cingulate deep brain stimulation for treatment-refractory anorexia nervosa: a phase 1 pilot trial. Lancet 381:1361-1370, 2013

167. Lopez AD, Mathers CD, Ezzati M, Jamison DT, Murray CJL: Measuring the global burden of disease and risk factors, 1990-2001, in Lopez AD, Mathers CD, Ezzati M, et al (eds): Global Burden of Disease and Risk Factors. Washington, DC: World Bank Group, 2006, pp 1-14

168. López B, Caro L, Pardiñas AF: Evidence of trepanations in a medieval population (13th-14th century) of northern Spain (Gormaz, Soria). Anthropol Sci 119:247-257, 2011

169. Lozano AM, Giacobbe P, Hamani C, Rizvi SJ, Kennedy SH, Kolivakis TT, et al: A multicenter pilot study of subcallosal cingulate area deep brain stimulation for treatmentresistant depression. J Neurosurg 116:315-322, 2012

170. Lozano AM, Mayberg HS, Giacobbe P, Hamani C, Craddock RC, Kennedy SH: Subcallosal cingulate gyrus deep brain stimulation for treatment-resistant depression. Biol Psychiatry 64:461-467, 2008

171. Łuczywek E, Mempel E: Stereotactic amygdalotomy in the light of neuropsychological investigations. Acta Neurochir (Wien) 23:221-223, 1976

172. Maciunas RJ, Maddux BN, Riley DE, Whitney CM, Schoenberg MR, Ogrocki PJ, et al: Prospective randomized double-blind trial of bilateral thalamic deep brain stimulation in adults with Tourette syndrome. J Neurosurg 107:1004-1014, 2007

173. MacLean PD: Psychosomatic disease and the "visceral brain". Recent developments bearing on the Papez theory of emotion. Psychosom Med 11:338-353, 1949

174. Makki MI, Behen M, Bhatt A, Wilson B, Chugani HT: Microstructural abnormalities of striatum and thalamus in children with Tourette syndrome. Mov Disord 23:2349 2356, 2008

175. Malakhova OE, Popovkin EM, Gudina IG: Efferent connections of various parts of the orbitofrontal cortex with the thalamic structures of the cat. Neurosci Behav Physiol 19:507-515, 1989

176. Mallet L, Mesnage V, Houeto JL, Pelissolo A, Yelnik J, Behar C, et al: Compulsions, Parkinson's disease, and stimulation. Lancet 360:1302-1304, 2002

177. Mallet L, Polosan M, Jaafari N, Baup N, Welter ML, Fontaine D, et al: Subthalamic nucleus stimulation in severe obsessive-compulsive disorder. N Engl J Med 359:21212134, 2008

178. Mallet L, Schüpbach M, N'Diaye K, Remy P, Bardinet E, Czernecki V, et al: Stimulation of subterritories of the subthalamic nucleus reveals its role in the integration of the emotional and motor aspects of behavior. Proc Natl Acad Sci U S A 104: 10661-10666, 2007

179. Malone DA Jr, Dougherty DD, Rezai AR, Carpenter LL, Friehs GM, Eskandar EN, et al: Deep brain stimulation of the ventral capsule/ventral striatum for treatment-resistant depression. Biol Psychiatry 65:267-275, 2009

180. Manjila S, Rengachary S, Xavier AR, Parker B, Guthikonda M: Modern psychosurgery before Egas Moniz: a tribute to Gottlieb Burckhardt. Neurosurg Focus 25(1):E9, 2008

181. Mantione M, van de Brink W, Schuurman PR, Denys D: Smoking cessation and weight loss after chronic deep brain stimulation of the nucleus accumbens: therapeutic and research implications: case report. Neurosurgery 66:E218, 2010

182. Mantovani A, Rossi S, Bassi BD, Simpson HB, Fallon BA, Lisanby SH: Modulation of motor cortex excitability in obsessive-compulsive disorder: an exploratory study on the relations of neurophysiology measures with clinical outcome. Psychiatry Res 210:1026-1032, 2013

183. Marceglia S, Servello D, Foffani G, Porta M, Sassi M, Mrakic-Sposta $S$, et al: Thalamic single-unit and local field potential activity in Tourette syndrome. Mov Disord 25:300-308, 2010

184. Martin-Soelch C: Is depression associated with dysfunction of the central reward system? Biochem Soc Trans 37:313317, 2009

185. Martínez-Fernández R, Zrinzo L, Aviles-Olmos I, Hariz M, Martinez-Torres I, Joyce E, et al: Deep brain stimulation for Gilles de la Tourette syndrome: a case series targeting subregions of the globus pallidus internus. Mov Disord 26:1922-1930, 2011

186. Martinez-Torres I, Hariz MI, Zrinzo L, Foltynie T, Limousin P: Improvement of tics after subthalamic nucleus deep brain stimulation. Neurology 72:1787-1789, 2009

187. Mashour GA, Walker EE, Martuza RL: Psychosurgery: past, present, and future. Brain Res Brain Res Rev 48:409-419, 2005

188. Mayberg HS, Brannan SK, Mahurin RK, Jerabek PA, Brickman JS, Tekell JL, et al: Cingulate function in depression: a potential predictor of treatment response. Neuroreport 8: 1057-1061, 1997

189. Mayberg HS, Brannan SK, Tekell JL, Silva JA, Mahurin RK, McGinnis S, et al: Regional metabolic effects of fluoxetine in major depression: serial changes and relationship to clinical response. Biol Psychiatry 48:830-843, 2000

190. Mayberg HS, Lozano AM, Voon V, McNeely HE, Seminowicz D, Hamani C, et al: Deep brain stimulation for treatment-resistant depression. Neuron 45:651-660, 2005

191. McLaughlin NC, Didie ER, Machado AG, Haber SN, Eskandar EN, Greenberg BD: Improvements in anorexia symptoms after deep brain stimulation for intractable obsessive-compulsive disorder. Biol Psychiatry 73:e29-e31, 2013 
192. McNeely HE, Mayberg HS, Lozano AM, Kennedy SH: Neuropsychological impact of Cg25 deep brain stimulation for treatment-resistant depression: preliminary results over 12 months. J Nerv Ment Dis 196:405-410, 2008

193. Mehler WR: Subcortical afferent connections of the amygdala in the monkey. J Comp Neurol 190:733-762, 1980

194. Merkl A, Schneider GH, Schönecker T, Aust S, Kühl KP, Kupsch A, et al: Antidepressant effects after short-term and chronic stimulation of the subgenual cingulate gyrus in treatment-resistant depression. Exp Neurol 249:160-168, 2013

195. Metzger CD, van der Werf YD, Walter M: Functional mapping of thalamic nuclei and their integration into cortico-striatal-thalamo-cortical loops via ultra-high resolution imaging - from animal anatomy to in vivo imaging in humans. Front Neurosci 7:24, 2013

196. Mindus P, Rasmussen SA, Lindquist C: Neurosurgical treatment for refractory obsessive-compulsive disorder: implications for understanding frontal lobe function. $\mathbf{J}$ Neuropsychiatry Clin Neurosci 6:467-477, 1994

197. Moniz E: Tentatives Operatoires dans le Traitement de Certaines Psychoses. Paris: Masson, 1936

198. Morgan JF, Crisp AH: Use of leucotomy for intractable anorexia nervosa: a long-term follow-up study. Int J Eat Disord 27:249-258, 2000

199. Motlagh MG, Smith ME, Landeros-Weisenberger A, Kobets AJ, King RA, Miravite J, et al: Lessons learned from openlabel deep brain stimulation for Tourette syndrome: eight cases over 7 years. Tremor Other Hyperkinet Mov (N Y) 3:tre-03-170-4428-1, 2013

200. Mottaghy FM, Keller CE, Gangitano M, Ly J, Thall M, Parker JA, et al: Correlation of cerebral blood flow and treatment effects of repetitive transcranial magnetic stimulation in depressed patients. Psychiatry Res 115:1-14, 2002

201. Mpakopoulou M, Gatos H, Brotis A, Paterakis KN, Fountas $\mathrm{KN}$ : Stereotactic amygdalotomy in the management of severe aggressive behavioral disorders. Neurosurg Focus 25(1):E6, 2008

202. Müller UJ, Sturm V, Voges J, Heinze HJ, Galazky I, Heldmann M, et al: Successful treatment of chronic resistant alcoholism by deep brain stimulation of nucleus accumbens: first experience with three cases. Pharmacopsychiatry 42:288-291, 2009

203. Müller-Vahl KR: Surgical treatment of Tourette syndrome. Neurosci Biobehav Rev 37:1178-1185, 2013

204. Narabayashi H, Nagao T, Saito Y, Yoshida M, Nagahata M: Stereotaxic amygdalotomy for behavior disorders. Arch Neurol 9:1-16, 1963

205. Narabayashi H, Uno M: Long range results of stereotaxic amygdalotomy for behavior disorders. Confin Neurol 27:168-171, 1966

206. Neimat JS, Patil PG, Lozano AM: Novel surgical therapies for Tourette syndrome. J Child Neurol 21:715-718, 2006

207. Neuner I, Kupriyanova Y, Stöcker T, Huang R, Posnansky $\mathrm{O}$, Schneider F, et al: Microstructure assessment of grey matter nuclei in adult Tourette patients by diffusion tensor imaging. Neurosci Lett 487:22-26, 2011

208. Neuner I, Podoll K, Lenartz D, Sturm V, Schneider F: Deep brain stimulation in the nucleus accumbens for intractable Tourette's syndrome: follow-up report of 36 months. Biol Psychiatry 65:e5-e6, 2009

209. Nobler MS, Oquendo MA, Kegeles LS, Malone KM, Campbell CC, Sackeim HA, et al: Decreased regional brain metabolism after ECT. Am J Psychiatry 158:305-308, 2001

210. Nuttin B, Cosyns P, Demeulemeester H, Gybels J, Meyerson B: Electrical stimulation in anterior limbs of internal capsules in patients with obsessive-compulsive disorder. Lancet 354:1526, 1999
211. Nuttin BJ, Gabriëls LA, Cosyns PR, Meyerson BA, Andréewitch S, Sunaert SG, et al: Long-term electrical capsular stimulation in patients with obsessive-compulsive disorder. Neurosurgery 52:1263-1272, discussion 1272-1274, 2003

212. Oh JS, Jang JH, Jung WH, Kang DH, Choi JS, Choi CH, et al: Reduced fronto-callosal fiber integrity in unmedicated OCD patients: a diffusion tractography study. Hum Brain Mapp 33:2441-2452, 2012

213. Okun MS, Bowers D, Springer U, Shapira NA, Malone D, Rezai AR, et al: What's in a "smile?" Intra-operative observations of contralateral smiles induced by deep brain stimulation. Neurocase 10:271-279, 2004

214. Okun MS, Foote KD, Wu SS, Ward HE, Bowers D, Rodriguez RL, et al: A trial of scheduled deep brain stimulation for Tourette syndrome: moving away from continuous deep brain stimulation paradigms. JAMA Neurol 70:85-94, 2013

215. Okun MS, Mann G, Foote KD, Shapira NA, Bowers D, Springer U, et al: Deep brain stimulation in the internal capsule and nucleus accumbens region: responses observed during active and sham programming. J Neurol Neurosurg Psychiatry 78:310-314, 2007

216. Orth M, Rothwell JC: Motor cortex excitability and comorbidity in Gilles de la Tourette syndrome. J Neurol Neurosurg Psychiatry 80:29-34, 2009

217. Pallanti S, Quercioli L: Treatment-refractory obsessive-compulsive disorder: methodological issues, operational definitions and therapeutic lines. Prog Neuropsychopharmacol Biol Psychiatry 30:400-412, 2006

218. Papez JW: A proposed mechanism of emotion. Arch Neurol Psychiatry 38:725-743, 1937

219. Parent A, Hazrati LN: Functional anatomy of the basal ganglia. II. The place of subthalamic nucleus and external pallidum in basal ganglia circuitry. Brain Res Brain Res Rev 20:128-154, 1995

220. Patel SR, Aronson JP, Sheth SA, Eskandar EN: Lesion procedures in psychiatric neurosurgery. World Neurosurg 80:S31.e9-S31.e16, 2013

221. Peterson BS, Choi HA, Hao X, Amat JA, Zhu H, Whiteman $\mathrm{R}$, et al: Morphologic features of the amygdala and hippocampus in children and adults with Tourette syndrome. Arch Gen Psychiatry 64:1281-1291, 2007

222. Peterson BS, Thomas P, Kane MJ, Scahill L, Zhang H, Bronen $\mathrm{R}$, et al: Basal ganglia volumes in patients with Gilles de la Tourette syndrome. Arch Gen Psychiatry 60:415-424, 2003

223. Piallat B, Polosan M, Fraix V, Goetz L, David O, Fenoy A, et al: Subthalamic neuronal firing in obsessive-compulsive disorder and Parkinson disease. Ann Neurol 69:793-802, 2011

224. Porta M, Brambilla A, Cavanna AE, Servello D, Sassi M, Rickards H, et al: Thalamic deep brain stimulation for treatment-refractory Tourette syndrome: two-year outcome. Neurology 73:1375-1380, 2009

225. Porta M, Servello D, Zanaboni C, Anasetti F, Menghetti C, Sassi M, et al: Deep brain stimulation for treatment of refractory Tourette syndrome: long-term follow-up. Acta Neurochir (Wien) 154:2029-2041, 2012

226. Posner J, Marsh R, Maia TV, Peterson BS, Gruber A, Simpson HB: Reduced functional connectivity within the limbic cortico-striato-thalamo-cortical loop in unmedicated adults with obsessive-compulsive disorder. Hum Brain Mapp 35:2852-2860, 2014

227. Pourfar M, Feigin A, Tang CC, Carbon-Correll M, Bussa M, Budman C, et al: Abnormal metabolic brain networks in Tourette syndrome. Neurology 76:944-952, 2011

228. Price JL: Comparative aspects of amygdala connectivity. Ann N Y Acad Sci 985:50-58, 2003 
229. Protopopescu X, Pan H, Tuescher O, Cloitre M, Goldstein $M$, Engelien W, et al: Differential time courses and specificity of amygdala activity in posttraumatic stress disorder subjects and normal control subjects. Biol Psychiatry 57:464-473, 2005

230. Puigdemont D, Pérez-Egea R, Portella MJ, Molet J, de Diego-Adeliño J, Gironell A, et al: Deep brain stimulation of the subcallosal cingulate gyrus: further evidence in treatment-resistant major depression. Int $\mathbf{J}$ Neuropsychopharmacol 15:121-133, 2012

231. Puigdemont D, Portella M, Pérez-Egea R, Molet J, Gironell A, de Diego-Adeliño J, et al: A randomized double-blind crossover trial of deep brain stimulation of the subcallosal cingulate gyrus in patients with treatment-resistant depression: a pilot study of relapse prevention. J Psychiatry Neurosci 40:130295, 2015

232. Ranft K, Dobrowolny H, Krell D, Bielau H, Bogerts B, Bernstein HG: Evidence for structural abnormalities of the human habenular complex in affective disorders but not in schizophrenia. Psychol Med 40:557-567, 2010

233. Rauch SL, Dougherty DD, Malone D, Rezai A, Friehs G, Fischman AJ, et al: A functional neuroimaging investigation of deep brain stimulation in patients with obsessive-compulsive disorder. J Neurosurg 104:558-565, 2006

234. Ressler KJ, Mayberg HS: Targeting abnormal neural circuits in mood and anxiety disorders: from the laboratory to the clinic. Nat Neurosci 10:1116-1124, 2007

235. Rickards H, Wood C, Cavanna AE: Hassler and Dieckmann's seminal paper on stereotactic thalamotomy for Gilles de la Tourette syndrome: translation and critical reappraisal. Mov Disord 23:1966-1972, 2008

236. Riva-Posse P, Holtzheimer PE, Garlow SJ, Mayberg HS: Practical considerations in the development and refinement of subcallosal cingulate white matter deep brain stimulation for treatment-resistant depression. World Neurosurg 80:S27.e25-S27.e34, 2013

237. Robertson MM: The Gilles de la Tourette syndrome: the current status. Arch Dis Child Educ Pract Ed 97:166-175, 2012

238. Robinson TE, Berridge KC: Review. The incentive sensitization theory of addiction: some current issues. Philos Trans R Soc Lond B Biol Sci 363:3137-3146, 2008

239. Robison RA, Taghva A, Liu CY, Apuzzo MLJ: Surgery of the mind, mood, and conscious state: an idea in evolution. World Neurosurg 80:S2-S26, 2013

240. Roh D, Chang WS, Chang JW, Kim CH: Long-term followup of deep brain stimulation for refractory obsessive-compulsive disorder. Psychiatry Res 200:1067-1070, 2012

241. Rosenow J, Das K, Rovit RL, Couldwell WT: Irving S. Cooper and his role in intracranial stimulation for movement disorders and epilepsy. Stereotact Funct Neurosurg 78:95-112, 2002

242. Rush AJ, Trivedi MH, Wisniewski SR, Nierenberg AA, Stewart JW, Warden D, et al: Acute and longer-term outcomes in depressed outpatients requiring one or several treatment steps: a STAR*D report. Am J Psychiatry 163:1905-1917, 2006

243. Salcman M: "The Cure of Folly" or "The Operation for the Stone" by Hieronymus Bosch (c. 1450-1516). Neurosurgery 59:935-937, 2006

244. Sano K, Mayanagi Y: Posteromedial hypothalamotomy in the treatment of violent, aggressive behaviour. Acta Neurochir Suppl (Wien) 44:145-151, 1988

245. Sano K, Mayanagi Y, Sekino H, Ogashiwa M, Ishijima B: Results of stimulation and destruction of the posterior hypothalamus in man. J Neurosurg 33:689-707, 1970

246. Sartorius A, Henn FA: Deep brain stimulation of the lateral habenula in treatment resistant major depression. Med Hypotheses 69:1305-1308, 2007
247. Savica R, Stead M, Mack KJ, Lee KH, Klassen BT: Deep brain stimulation in Tourette syndrome: a description of 3 patients with excellent outcome. Mayo Clin Proc 87:5962,2012

248. Saxena S, Brody AL, Schwartz JM, Baxter LR: Neuroimaging and frontal-subcortical circuitry in obsessive-compulsive disorder. Br J Psychiatry Suppl 35:26-37, 1998

249. Saxena S, Rauch SL: Functional neuroimaging and the neuroanatomy of obsessive-compulsive disorder. Psychiatr Clin North Am 23:563-586, 2000

250. Scheibel ME, Scheibel AB: Structural organization of nonspecific thalamic nuclei and their projection toward cortex. Brain Res 6:60-94, 1967

251. Schlaepfer TE, Bewernick BH: Deep brain stimulation for major depression. Handb Clin Neurol 116:235-243, 2013

252. Schlaepfer TE, Cohen MX, Frick C, Kosel M, Brodesser D, Axmacher N, et al: Deep brain stimulation to reward circuitry alleviates anhedonia in refractory major depression. Neuropsychopharmacology 33:368-377, 2008

253. Schlaepfer TE, George MS, Mayberg H: WFSBP guidelines on brain stimulation treatments in psychiatry. World J Biol Psychiatry 11:2-18, 2010

254. Schrock LE, Mink JW, Woods DW, Porta M, Servello $\mathrm{D}$, Visser-Vandewalle V, et al: Tourette syndrome deep brain stimulation: A review and updated recommendations: Tourette Syndrome DBS Guidelines. Mov Disord 30:448471,2015

255. Schvarcz JR, Driollet R, Rios E, Betti O: Stereotactic hypothalamotomy for behaviour disorders. J Neurol Neurosurg Psychiatry 35:356-359, 1972

256. Servello D, Porta M, Sassi M, Brambilla A, Robertson MM: Deep brain stimulation in 18 patients with severe Gilles de la Tourette syndrome refractory to treatment: the surgery and stimulation. J Neurol Neurosurg Psychiatry 79:136142,2008

257. Servello D, Sassi M, Brambilla A, Defendi S, Porta M: Long-term, post-deep brain stimulation management of a series of 36 patients affected with refractory Gilles de la Tourette syndrome. Neuromodulation 13:187-194, 2010

258. Shahed J, Poysky J, Kenney C, Simpson R, Jankovic J: GPi deep brain stimulation for Tourette syndrome improves tics and psychiatric comorbidities. Neurology 68:159-160, 2007

259. Shahed J, Poysky J, Kenney C, Simpson R, Jankovic J: Motor and behavioral outcomes after bilateral GPi deep brain stimulation for severe Tourette syndrome. Mov Disord (Suppl 16):S283, 2007 (Abstract)

260. Shapira NA, Okun MS, Wint D, Foote KD, Byars JA, Bowers D, et al: Panic and fear induced by deep brain stimulation. J Neurol Neurosurg Psychiatry 77:410-412, 2006

261. Shepherd GMG: Corticostriatal connectivity and its role in disease. Nat Rev Neurosci 14:278-291, 2013

262. Sheth SA, Neal J, Tangherlini F, Mian MK, Gentil A, Cosgrove GR, et al: Limbic system surgery for treatmentrefractory obsessive-compulsive disorder: a prospective long-term follow-up of 64 patients. J Neurosurg 118:491497, 2013

263. Shields DC, Cheng ML, Flaherty AW, Gale JT, Eskandar EN: Microelectrode-guided deep brain stimulation for Tourette syndrome: within-subject comparison of different stimulation sites. Stereotact Funct Neurosurg 86:87-91, 2008

264. Shumake J, Edwards E, Gonzalez-Lima F: Opposite metabolic changes in the habenula and ventral tegmental area of a genetic model of helpless behavior. Brain Res 963:274281,2003

265. Singer HS, Dickson J, Martinie D, Levine M: Second messenger systems in Tourette's syndrome. J Neurol Sci 128:78-83, 1995 
266. Singer HS, Szymanski S, Giuliano J, Yokoi F, Dogan AS, Brasic JR, et al: Elevated intrasynaptic dopamine release in Tourette's syndrome measured by PET. Am J Psychiatry 159:1329-1336, 2002

267. Skinner JE: Abolition of several forms of cortical synchronization during blockade in the inferior thalamic peduncle. Electroencephalogr Clin Neurophysiol 31:211-221, 1971

268. Sowell ER, Kan E, Yoshii J, Thompson PM, Bansal R, Xu $\mathrm{D}$, et al: Thinning of sensorimotor cortices in children with Tourette syndrome. Nat Neurosci 11:637-639, 2008

269. Strober M, Freeman R, Morrell W: The long-term course of severe anorexia nervosa in adolescents: survival analysis of recovery, relapse, and outcome predictors over $10-15$ years in a prospective study. Int J Eat Disord 22:339-360, 1997

270. Sturm V, Fricke O, Bührle CP, Lenartz D, Maarouf M, Treuer H, et al: DBS in the basolateral amygdala improves symptoms of autism and related self-injurious behavior: a case report and hypothesis on the pathogenesis of the disorder. Front Hum Neurosci 6:341, 2012

271. Sturm V, Lenartz D, Koulousakis A, Treuer H, Herholz K, Klein JC, et al: The nucleus accumbens: a target for deep brain stimulation in obsessive-compulsive- and anxietydisorders. J Chem Neuroanat 26:293-299, 2003

272. Swedo SE, Schapiro MB, Grady CL, Cheslow DL, Leonard HL, Kumar A, et al: Cerebral glucose metabolism in childhood-onset obsessive-compulsive disorder. Arch Gen Psychiatry 46:518-523, 1989

273. Taira T, Kobayashi T, Hori T: Disappearance of self-mutilating behavior in a patient with Lesch-Nyhan syndrome after bilateral chronic stimulation of the globus pallidus internus. Case report. J Neurosurg 98:414-416, 2003

274. Talairach J, Hecaen H, David M: Lobotomie prefrontale limitee par electrocoagulation des fibres thalamo-frontalis leur emergence du bras anterior de la capsule interne, in Proceedings of the 4th Congress Neurologique Internationale. Paris: Masson, 1949, p 141

275. Temel Y, Kessels A, Tan S, Topdag A, Boon P, VisserVandewalle V: Behavioural changes after bilateral subthalamic stimulation in advanced Parkinson disease: a systematic review. Parkinsonism Relat Disord 12:265-272, 2006

276. Thibault G, O'Connor KP, Stip E, Lavoie ME: Electrophysiological manifestations of stimulus evaluation, response inhibition and motor processing in Tourette syndrome patients. Psychiatry Res 167:202-220, 2009

277. Tobe RH, Bansal R, Xu D, Hao X, Liu J, Sanchez J, et al: Cerebellar morphology in Tourette syndrome and obsessivecompulsive disorder. Ann Neurol 67:479-487, 2010

278. Tremblay LK, Naranjo CA, Graham SJ, Herrmann N, Mayberg HS, Hevenor S, et al: Functional neuroanatomical substrates of altered reward processing in major depressive disorder revealed by a dopaminergic probe. Arch Gen Psychiatry 62:1228-1236, 2005

279. Tueth MJ: Schizophrenia: Emil Kraepelin, Adolph Meyer, and beyond. J Emerg Med 13:805-809, 1995

280. Valencia-Alfonso CE, Luigjes J, Smolders R, Cohen MX, Levar N, Mazaheri A, et al: Effective deep brain stimulation in heroin addiction: a case report with complementary intracranial electroencephalogram. Biol Psychiatry 71:e35-e37, 2012

281. van der Kolk BA, Pelcovitz D, Roth S, Mandel FS, McFarlane A, Herman JL: Dissociation, somatization, and affect dysregulation: the complexity of adaptation of trauma. Am J Psychiatry 153 (7 Suppl):83-93, 1996

282. van Kuyck K, Gérard N, Van Laere K, Casteels C, Pieters G, Gabriëls L, et al: Towards a neurocircuitry in anorexia nervosa: evidence from functional neuroimaging studies. J Psychiatr Res 43:1133-1145, 2009

283. Van Laere K, Nuttin B, Gabriels L, Dupont P, Rasmussen $\mathrm{S}$, Greenberg BD, et al: Metabolic imaging of anterior capsular stimulation in refractory obsessive-compulsive disorder: a key role for the subgenual anterior cingulate and ventral striatum. J Nucl Med 47:740-747, 2006

284. van Woerkom TC, Roos RA, van Dijk JG: Altered attentional processing of background stimuli in Gilles de la Tourette syndrome: a study in auditory event-related potentials evoked in an oddball paradigm. Acta Neurol Scand 90:116-123, 1994

285. Vandewalle V, van der Linden C, Groenewegen HJ, Caemaert J: Stereotactic treatment of Gilles de la Tourette syndrome by high frequency stimulation of thalamus. Lancet 353:724, 1999

286. Vassoler FM, Schmidt HD, Gerard ME, Famous KR, Ciraulo DA, Kornetsky C, et al: Deep brain stimulation of the nucleus accumbens shell attenuates cocaine priminginduced reinstatement of drug seeking in rats. J Neurosci 28:8735-8739, 2008

287. Velasco F, Velasco M, Jiménez F, Velasco AL, SalinPascual R: Neurobiological background for performing surgical intervention in the inferior thalamic peduncle for treatment of major depression disorders. Neurosurgery 57:439-448, 2005

288. Velasco M, Lindsley DB: Role of orbital cortex in regulation of thalamocortical electrical activity. Science 149:1375-1377, 1965

289. Vernaleken I, Kuhn J, Lenartz D, Raptis M, Huff W, Janouschek H, et al: Bithalamical deep brain stimulation in Tourette syndrome is associated with reduction in dopaminergic transmission. Biol Psychiatry 66:e15-e17, 2009

290. Visser-Vandewalle V, Temel Y, Boon P, Vreeling F, Colle H, Hoogland G, et al: Chronic bilateral thalamic stimulation: a new therapeutic approach in intractable Tourette syndrome. Report of three cases. J Neurosurg 99:1094-1100, 2003

291. Voges J, Müller U, Bogerts B, Münte T, Heinze HJ: Deep brain stimulation surgery for alcohol addiction. World Neurosurg 80:S28.e21-S28.e31, 2013

292. Wang J, Chang C, Geng N, Wang X, Gao G: Treatment of intractable anorexia nervosa with inactivation of the nucleus accumbens using stereotactic surgery. Stereotact Funct Neurosurg 91:364-372, 2013

293. Welter ML, Burbaud P, Fernandez-Vidal S, Bardinet E, Coste J, Piallat B, et al: Basal ganglia dysfunction in OCD: subthalamic neuronal activity correlates with symptoms severity and predicts high-frequency stimulation efficacy. Transl Psychiatry 1:e5, 2011

294. Welter ML, Mallet L, Houeto JL, Karachi C, Czernecki V, Cornu P, et al: Internal pallidal and thalamic stimulation in patients with Tourette syndrome. Arch Neurol 65:952-957, 2008

295. Wernicke C: The symptom-complex of aphasia, in Church A (ed): Modern Clinical Medicine: Diseases of the Nervous System. New York: D. Appleton, 1910, pp 265324

296. Whiteside SP, Port JD, Abramowitz JS: A meta-analysis of functional neuroimaging in obsessive-compulsive disorder. Psychiatry Res 132:69-79, 2004

297. Whitty CWM, Duffield JE, Tov' PM, Cairns H: Anterior cingulectomy in the treatment of mental disease. Lancet 1:475-481, 1952

298. Wind JJ, Anderson DE: From prefrontal leukotomy to deep brain stimulation: the historical transformation of psychosurgery and the emergence of neuroethics. Neurosurg Focus 25(1):E10, 2008

299. Wise RA: Brain reward circuitry: insights from unsensed incentives. Neuron 36:229-240, 2002

300. Wise RA: Forebrain substrates of reward and motivation. J Comp Neurol 493:115-121, 2005

301. Wong DF, Brasić JR, Singer HS, Schretlen DJ, Kuwabara 
H, Zhou Y, et al: Mechanisms of dopaminergic and serotonergic neurotransmission in Tourette syndrome: clues from an in vivo neurochemistry study with PET. Neuropsychopharmacology 33:1239-1251, 2008

302. Worbe Y, Marrakchi-Kacem L, Lecomte S, Valabregue R, Poupon F, Guevara P, et al: Altered structural connectivity of cortico-striato-pallido-thalamic networks in Gilles de la Tourette syndrome. Brain 138:472-482, 2015

303. Wu H, Van Dyck-Lippens PJ, Santegoeds R, van Kuyck K, Gabriels L, Lin G, et al: Deep-brain stimulation for anorexia nervosa. World Neurosurg 80:S29.e1-S29.e10, 2013

304. Wu HM, Wang XL, Chang CW, Li N, Gao L, Geng N, et al: Preliminary findings in ablating the nucleus accumbens using stereotactic surgery for alleviating psychological dependence on alcohol. Neurosci Lett 473:77-81, 2010

305. Xu J, Wang G, Zhou H, Tian Z, Luo Q, Jiang J: [Neurosurgical treatment on alleviating heroin psychological dependence.] Chin J Neurosurg 10:590-593, 2005 (Chinese)

306. Xu M, Kobets A, Du JC, Lennington J, Li L, Banasr M, et al: Targeted ablation of cholinergic interneurons in the dorsolateral striatum produces behavioral manifestations of Tourette syndrome. Proc Natl Acad Sci U S A 112:893898,2015

307. Zabek M, Sobstyl M, Koziara H, Dzierzecki S: Deep brain stimulation of the right nucleus accumbens in a patient with Tourette syndrome. Case report. Neurol Neurochir Pol 42:554-559, 2008

308. Zahm DS: The evolving theory of basal forebrain functional-anatomical 'macrosystems'. Neurosci Biobehav Rev 30:148-172, 2006
309. Zamboni R, Larach V, Poblete M, Mancini R, Mancini $\mathrm{H}$, Charlin V, et al: Dorsomedial thalamotomy as a treatment for terminal anorexia: a report of two cases. Acta Neurochir Suppl (Wien) 58:34-35, 1993

310. Zhou H, Xu J, Jiang J: Deep brain stimulation of nucleus accumbens on heroin-seeking behaviors: a case report. Biol Psychiatry 69:e41-e42, 2011

311. Zipfel S, Löwe B, Reas DL, Deter HC, Herzog W: Longterm prognosis in anorexia nervosa: lessons from a 21-year follow-up study. Lancet 355:721-722, 2000

\section{Author Contributions}

Conception and design: Ko, Cleary, Ozpinar. Acquisition of data: Cleary. Drafting the article: Ko, Cleary, Ozpinar. Critically revising the article: Ko, Raslan. Reviewed submitted version of manuscript: Cleary. Study supervision: Ko.

\section{Supplemental Information \\ Current Affiliation}

Dr. Cleary: Division of Neurosurgery, University of California, San Diego, San Diego, California.

\section{Correspondence}

Andrew L. Ko, Department of Neurosurgery, University of Washington, 1959 N.E. Pacific St., Seattle, WA 98195. email: alko00@neurosurgery.washington.edu. 